\title{
Pituitary Adenylate Cyclase-Activating Polypeptide Induces Postsynaptically Expressed Potentiation in the Intra-amygdala Circuit
}

\author{
Jun-Hyeong Cho, ${ }^{1}$ Ko Zushida, ${ }^{2}$ Gleb P. Shumyatsky, ${ }^{2}$ William A. Carlezon Jr, ${ }^{1}$ Edward G. Meloni, ${ }^{1}$ \\ and Vadim Y. Bolshakov ${ }^{1}$ \\ 'Department of Psychiatry, McLean Hospital, Harvard Medical School, Belmont, Massachusetts 02478, and ²Department of Genetics, Rutgers University, \\ Piscataway, New Jersey 08854
}

Pituitary adenylate cyclase-activating polypeptide (PACAP) is a pleiotropic neuropeptide expressed in the brain, where it may act as a neuromodulator or neurotransmitter contributing to different behavioral processes and stress responses. PACAP is highly expressed in the amygdala, a subcortical brain area involved in both innate and learned fear, suggesting a role for PACAP-mediated signaling in fear-related behaviors. It remains unknown, however, whether and how PACAP affects neuronal and synaptic functions in the amygdala. In this study, we focused on neurons in the lateral division of the central nucleus (CeL), where PACAP-positive presynaptic terminals were predominantly found within the amygdala. In our experiments on rat brain slices, exogenous application of PACAP did not affect either resting membrane potential or membrane excitability of CeL neurons. PACAP enhanced, however, excitatory synaptic transmission in projections from the basolateral nucleus (BLA) to the CeL, while inhibitory transmission in the same pathway was unaffected. PACAPinduced potentiation of glutamatergic synaptic responses persisted after the washout of PACAP and was blocked by the VPAC1 receptor antagonist, suggesting that VPAC1 receptors might mediate synaptic effects of PACAP in the CeL. Moreover, potentiation of synaptic transmission by PACAP was dependent on postsynaptic activation of protein kinase A and calcium/calmodulin-dependent protein kinase II, as well as synaptic targeting of GluR1 subunit-containing AMPA receptors. Thus, PACAP may upregulate excitatory neurotransmission in the BLA-CeL pathway postsynaptically, consistent with the known roles of PACAP in control of fear-related behaviors.

\section{Introduction}

Pituitary adenylate cyclase-activating polypeptide (PACAP) is an excitatory neuropeptide, originally isolated from hypothalamic tissue, which was found to increase the production of cAMP in mammalian anterior pituitary cells (Miyata et al., 1989). Subsequent studies revealed that PACAP is expressed in various areas throughout the brain (Köves et al., 1991; Basille et al., 2000), where it serves neurotrophic, neuromodulatory, and neurotransmitting functions (Masuo et al., 1993; Stella and Magistretti, 1996; Villalba et al., 1997; Roberto et al., 2001; Nielsen et al., 2004) (for review, see Vaudry et al., 2009), binding to three different G-protein-coupled receptors with similar affinity. One receptor, PAC1, is specific to actions of PACAP, while two other receptors, VPAC1 and VPAC2, are shared by PACAP and vasoactive intestinal peptide (VIP) (Ishihara et al., 1992; Pisegna and Wank, 1993). As a neuromodulator, PACAP may control the

\footnotetext{
Received March 21, 2012; revised July 26, 2012; accepted Aug. 6, 2012.

Author contributions: J.-H.C., G.P.S., E.G.M., and V.Y.B. designed research; J.-H.C., K.Z., G.P.S., W.A.C., and E.G.M. performed research; W.A.C. contributed unpublished reagents/analytic tools; J.-H.C., K.Z., G.P.S., W.A.C., E.G.M., and V.Y.B. analyzed data; J.-H.C. and V.Y.B. wrote the paper.

This work was supported by National Institutes of Health Grants MH090464 (V.Y.B.), MH097860 (W.A.C.), and MH080328 (G.P.S.), and Whitehall Foundation (G.P.S., V.Y.B.). We thank Yan Li for comments on this manuscript.

Correspondence should be addressed to Dr. Vadim Y. Bolshakov at the above address. E-mail: vadimb@mclean.harvard.edu.

DOI:10.1523/JNEUROSCI.1402-12.2012

Copyright $\odot 2012$ the authors $\quad 0270-6474 / 12 / 3214165-13 \$ 15.00 / 0$
}

release of hormones and regulate neurotransmission and plasticity by activating different signaling molecules, including adenylate cyclase, phospholipase C, MAPK (mitogen-activated protein kinase), and increasing intracellular $\mathrm{Ca}^{2+}$ concentration (Hashimoto et al., 1993; Sreedharan et al., 1994; Macdonald et al., 2005; Vaudry et al., 2009; Yang et al., 2010). At the behavioral level, PACAP was shown to regulate many pivotal functions, such as food intake, psychomotor activity, stress responses, and learning and memory (Hashimoto et al., 2001, 2006; Otto et al., 2001a; Hammack et al., 2010).

Notably, previous studies provided several lines of evidence for the involvement of PACAP in regulation of fear-related behavioral processes. Thus, PACAP-containing fibers and PACAP receptors are densely expressed in the amygdala, a subcortical brain area essential for innate and learned fear (Piggins et al., 1996; Shioda et al., 1997; Kozicz and Arimura, 2002; Joo et al., 2004; Shumyatsky et al., 2005; Pape and Pare, 2010). Consistent with this expression pattern, direct infusions of PACAP into the central nucleus of the amygdala had an anxiogenic effect, resulting in a shift from an active to passive mode of responding to an aversive stimulus (Legradi et al., 2007). Moreover, genetically modified mice lacking either PACAP or type I PACAP receptor (PAC1) exhibited reduced anxiety levels (Hashimoto et al., 2001; Otto et al., 2001b), suggesting that endogenous PACAP may regulate innate fear. Finally, it was demonstrated recently that PACAP blood level may predict symptoms of posttraumatic 

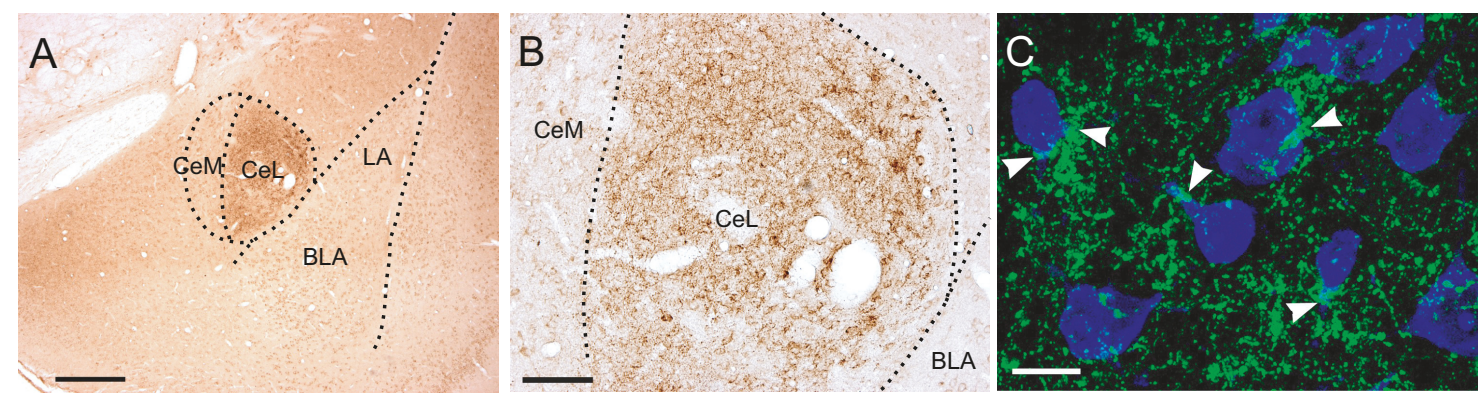

Figure 1. PACAP-positive nerve fibers innervate the lateral division of the CeA.A, A low-magnification image of coronal section through the amygdala showing PACAP staining (DAB chromagen; brown) in the CeA. LA and BLA, Lateral and basolateral nuclei of the amygdala. CeL and CeM, Lateral and medial divisions of the CeA, respectively. $\boldsymbol{B}$, A high-magnification image of PACAP staining in the CeL shown in $\boldsymbol{A}$. C, Fluorescent Nissl staining (NeuroTrace) of neurons in the Cel combined with immunohistochemistry for PACAP. The arrowheads indicate "collar-like" contacts by PACAP-containing fibers (labeled green) on proximal dendrites of CeL neurons with fluorescent Nissl staining that is labeled blue. Scale bars: $\boldsymbol{A}, 500 \mu \mathrm{m} ; \boldsymbol{B}, 100 \mu \mathrm{m} ; \boldsymbol{C}, 10 \mu \mathrm{m}$.

stress disorder in human female subjects exhibiting abnormally enhanced fear responses (Ressler et al., 2011). These previous findings suggest a possibility that PACAP may regulate anxietylike behaviors by modulating neuronal and synaptic activity in the components of innate fear circuitry, such as the amygdala, yet very little is known about the effects of PACAP in the amygdala at the cellular and molecular level. Here, we show that PACAPcontaining fibers are abundant in the lateral division of the central nucleus of the amygdala (CeL), and that PACAP facilitates neurotransmission at excitatory glutamatergic projections from the basolateral nucleus (BLA) to the CeL, a projection known to be implicated in responses to innately aversive stimuli (Tye et al., 2011), through postsynaptically expressed synaptic strengthening.

\section{Materials and Methods}

PACAP immunohistochemistry. Sprague Dawley rats (350-375 g) of either sex were killed by an overdose of sodium pentobarbitol $(130 \mathrm{mg} / \mathrm{kg})$ and perfused intracardially with $0.9 \%$ saline $(200 \mathrm{ml})$ followed by $2 \%$ paraformaldehyde, $0.05 \%$ glutaraldehyde, and $0.2 \%$ picric acid in $0.1 \mathrm{M}$ PBS (500 ml). After the fixation, the brains were stored for $4 \mathrm{~d}$ in a $30 \%$ sucrose $/ 0.1 \mathrm{M} \mathrm{PBS}, \mathrm{pH} 7.4$, solution at $4^{\circ} \mathrm{C}$, and subsequently, $20 \mu \mathrm{m}$ frozen sections were cut through the amygdala. Every third section through the rostrocaudal extent of the amygdala was then collected in glass vials for immunoprocessing using the avidin-biotin peroxidase (ABC) method (Hsu et al., 1981). All incubations were performed on a rocker (low setting) at room temperature. Briefly, the sections were incubated in $0.6 \%$ hydrogen peroxide in $0.1 \mathrm{M} \mathrm{PBS}, \mathrm{pH} 7.4$, for $30 \mathrm{~min}$ to eliminate endogenous peroxidase activity. To reduce nonspecific binding, the sections were preincubated in the blocking solution (2\% normal donkey serum, $1 \%$ bovine serum albumin, $0.3 \%$ Triton X-100 in $0.1 \mathrm{M}$ PBS, pH 7.4) for $2 \mathrm{~h}$ followed by incubation for $24 \mathrm{~h}$ with the rabbit polyclonal primary antibody against PACAP38 (1:1000; Bachem Americas). The sections were washed with PBS and incubated for $1 \mathrm{~h}$ with donkey anti-rabbit biotinylated secondary antibody (1:400; minimum species cross-reactivity; Jackson ImmunoResearch Laboratories). The sections were washed with PBS and incubated for $30 \mathrm{~min}$ with the avidinbiotin complex (Vector Laboratories). The sections were then incubated for $5 \mathrm{~min}$ in 3,3'-diaminobenzidine (DAB) $/ \mathrm{H}_{2} \mathrm{O}_{2}$ (SigmaFast; SigmaAldrich) as a chromagen for visualization of PACAP38 reaction product. Sections were mounted on gelatin-coated slides and coverslipped with Permount (Thermo Fisher Scientific).

Fluorescent immunohistochemistry. Alternate sections through the amygdala were cut to determine whether PACAP was localized in amygdala principal neurons. Briefly, sections were preincubated in the blocking solution for $2 \mathrm{~h}$ followed by incubation for $24 \mathrm{~h}$ with rabbit polyclonal primary antibody against PACAP38. Sections were washed with PBS and incubated for $1.5 \mathrm{~h}$ with Alexa Fluor 488-conjugated donkey anti-rabbit secondary antibody (Invitrogen). Sections were then incubated in NeuroTrace 640/660 deep-red fluorescent Nissl stain (1:200;
Invitrogen) in $0.1 \mathrm{M}$ PBS for $20 \mathrm{~min}$. Sections were mounted under low light on gelatin-coated slides using Gel Mount (Sigma-Aldrich).

Light (DAB-processed section) microscopy of PACAP-positive fibers in the amygdala sections was performed using Zeiss Axioskop 2 microscope. Still frame images were captured with a digital camera (AxioCam; Zeiss) interfaced with a Macintosh G4 computer. PACAP innervation of Nissl-labeled neurons in the amygdala was further imaged using a Leica TSC NT laser-scanning confocal microscope (Leica Microsystems).

Cloning of the rat VPAC1R $c D N A$ and generation of the riboprobes for in situ hybridization. To clone the VPAC1R cDNA, total RNA was isolated from the rat brain using total RNA purification kit (QIAGEN). One microgram of total RNA was reverse-transcribed using oligo-dT 16 (Applied Biosystems). Double-stranded cDNA was amplified by PCR. The pairs of primers designed to amplify the VPAC1R were as follows: forward, GCCCCCATCCTCCTCTCCATC; reverse, TCCGCCTGCACCTCACCATTG. The PCR-amplified product was cloned into pCRII-TOPO vector (Invitrogen). The construct was checked by restriction analysis and sequencing. The VPAC1R antisense riboprobes were generated from the plasmid linearized with HindIII and transcribed with T7 RNA polymerase. The sense riboprobes were synthesized after linearization with $\mathrm{XbaI}$ and transcription with SP6 RNA polymerase. Riboprobes were transcribed in the presence of DIG-UTP (Roche).

Coronal sections from fresh-frozen rat brains were cut at $20 \mu \mathrm{m}$ thickness on the cryostat (Leica) and hybridized according to the published protocol with modifications (Schaeren-Wiemers and Gerfin-Moser, 1993). Briefly, the sections were fixed with $4 \%$ paraformaldehyde in $0.1 \mathrm{M}$ PBS, pH 7.4, for 10 min, rinsed in PBS treated with diethylpyrocarbonate (DEPC), and treated with acetic anhydride in $0.1 \mathrm{M}$ triethanolamine/ distilled water for $10 \mathrm{~min}$ at room temperature. Next, the sections were washed in PBS-DEPC solution, and incubated in prehybridization buffer (50\% formamide, $5 \times$ SSC, $5 \times$ Denhardt's, $250 \mu \mathrm{g} / \mathrm{ml}$ Escherichia coli tRNA, and $500 \mu \mathrm{g} / \mathrm{ml}$ herring sperm DNA) for $1 \mathrm{~h}$ at room temperature. Hybridization was performed overnight at $45^{\circ} \mathrm{C}$ in prehybridization buffer. After hybridization, the sections were washed in $5 \times$ SSC at $45^{\circ} \mathrm{C}$. After high-stringency washing [three times in $0.2 \times \mathrm{SSC}$ at $45^{\circ} \mathrm{C}$ followed by $0.2 \times$ SSC at room temperature and B1 ( $0.1 \mathrm{M}$ Tris- $\mathrm{HCl}, \mathrm{pH} 7.5,0.15 \mathrm{M}$ $\mathrm{NaCl})$ ], the sections were processed for immunological detection of DIG-labeled probes with alkaline phosphatase (AP)-conjugated antiDIG antibody (Roche) overnight at $4^{\circ} \mathrm{C}$. The AP reaction was visualized by NBT/BCIP (Promega).

Electrophysiological recordings. Brains were dissected quickly from 30to 34-d-old Sprague Dawley rats of either sex after decapitation, and chilled in ice-cold $\mathrm{Ca}^{2+}$-free artificial CSF (ACSF) containing $125 \mathrm{~mm}$ $\mathrm{NaCl}, 2.5 \mathrm{~mm} \mathrm{KCl}, 3.5 \mathrm{~mm} \mathrm{MgSO}_{4}, 1.25 \mathrm{~mm} \mathrm{NaH}_{2} \mathrm{PO}_{4}, 26 \mathrm{~mm} \mathrm{NaHCO}_{3}$, $10 \mathrm{~mm}$ glucose, and equilibrated with $95 \% \mathrm{O}_{2}$ and $5 \% \mathrm{CO}_{2}$. Coronal brain slices containing the amygdala ( $300 \mu \mathrm{m}$ thick) were prepared with a vibratome. Slices were recovered in the standard $\mathrm{Ca}^{2+}$-containing ACSF (125 mm NaCl, $2.5 \mathrm{~mm} \mathrm{KCl,} 2.5 \mathrm{~mm} \mathrm{CaCl}_{2}, 1 \mathrm{~mm} \mathrm{MgSO}_{4}, 1.25 \mathrm{~mm}$ $\mathrm{NaH}_{2} \mathrm{PO}_{4}, 26 \mathrm{~mm} \mathrm{NaHCO}_{3}, 10 \mathrm{~mm}$ glucose, and equilibrated with $95 \%$ $\mathrm{O}_{2}$ and $\left.5 \% \mathrm{CO}_{2}, \mathrm{pH} 7.3-7.4\right)$ for at least an hour at room temperature $\left(22-25^{\circ} \mathrm{C}\right)$, and used for experiments up to $5 \mathrm{~h}$ after preparation. Slices 
A
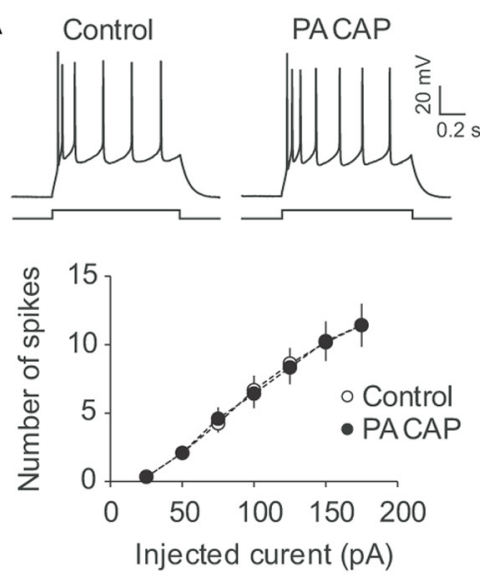

C
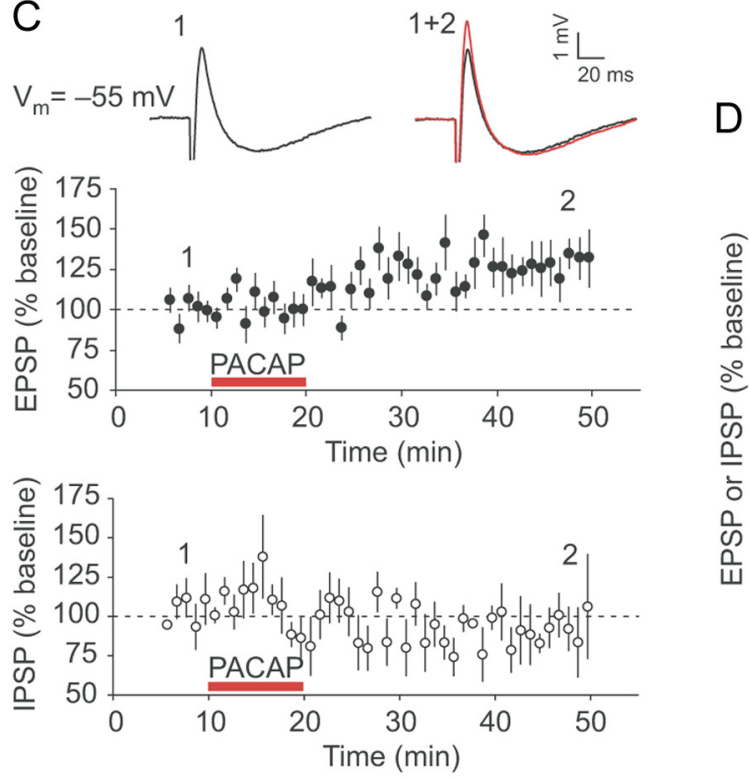

$E$
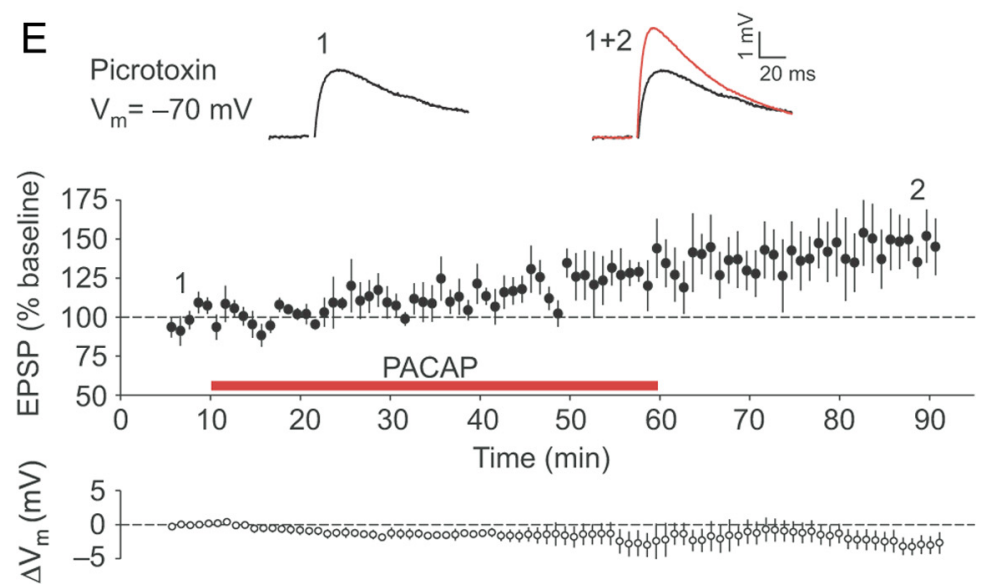

Figure 2. PACAP potentiates excitatory transmission in the BLA to the CeL pathway. $\boldsymbol{A}$, Summary plots of the number of action potentials in CeL neurons evoked by current injections of increasing intensity before (open circles) and after $10 \mathrm{~min}$ application of PACAP38 ( $5 \mathrm{~nm}$; filled circles; $n=6$ ). The traces on top represent responses of CeL neurons to depolarizing current injection ( $100 \mathrm{pA}$; $1 \mathrm{~s}$ ) recorded in current-clamp mode under control conditions and after application of PACAP38. B, Representation of the slice preparation, showing locations of stimulation (Stim) and recording (Rec) electrodes. Synaptic responses were evoked by stimulation of the BLA and recorded from neurons in the CeL. C, Summary graphs demonstrating the time course of EPSP (top graph, filled circles; $n=10$ ) and IPSP (bottom graph, open circles; $n=5$ ) amplitude changes produced by PACAP38 application (red horizontal bars). The insets show the average of 10 biphasic synaptic responses in a CeL neuron before (black trace) and after (red trace) PACAP38 application. The EPSP/IPSP sequences were recorded at a slightly depolarized membrane potential $(-55 \mathrm{mV})$ to increase the driving force for $\mathrm{Cl}^{-}$currents underlying $\mathrm{SABA}_{A}$ receptor-mediated IPSPS. D, Summary of the EPSP $(n=10)$ and IPSP $(n=5)$ amplitude changes 35-40 min after the start of PACAP application for the experiments shown in $\boldsymbol{C}$. The larger filled circles were placed in the recording chamber and perfused continuously with the standard ACSF $(\sim 1 \mathrm{ml}$ per minute). Picrotoxin (PTX) $(50 \mu \mathrm{M})$ was added to the ACSF to inhibit fast GABAergic transmission unless indicated otherwise. Whole-cell recordings were obtained from neurons in the lateral division of the CeA under visual guidance (infrared differential interference contrast optics) with an EPC-9 amplifier and Pulse, version 8.54, software (Heka Elektronik) as described earlier (Shin et al., 2006; Cho et al., 2012). The patch electrodes (3-5 M $\Omega$ resistance) contained $150 \mathrm{~mm}$ K-gluconate, $5 \mathrm{~mm} \mathrm{NaCl}, 1$ $\mathrm{mm} \mathrm{MgCl}_{2}, 10 \mathrm{~mm}$ HEPES, 0.2 EGTA, $4 \mathrm{~mm}$ MgATP, and $1.2 \mathrm{~mm} \mathrm{NaGTP} \mathrm{(adjusted} \mathrm{to} \mathrm{pH}$ 7.25 with $\mathrm{KOH}, 280-290 \mathrm{mOsm})$. In the experiments in which the EPSC $_{\text {AMPAR }} /$ EPSC $_{\text {NMDAR }}$ ratio was determined or NMDAR EPSCs were recorded, $140 \mathrm{~mm}$ Cs-methanesulfonate was substituted for K-gluconate. Synaptic responses were filtered at $1 \mathrm{kHz}$ and digitized at $2.5 \mathrm{kHz}$. Input and series resistances were monitored throughout the experiment, and the experiment was terminated when series resistance changed by $>20 \%$. Series resistance was not compensated. EPSCs or EPSPs in the CeL neurons were evoked by a bipolar stimulation electrode with $115 \mu \mathrm{m}$ spacing (FHC), which was placed within the BLA $\sim 250 \mu$ m laterally to the border between the BLA and the $\mathrm{CeA}$, with the square current pulses (50$250 \mu \mathrm{A} ; 100 \mu$ s duration) using Master-8 Pulse Stimulator (AMPI). Stimulation intensity was adjusted in individual experiments to evoke the EPSCs of 50-150 pA amplitude. Membrane potential was held constant at $-70 \mathrm{mV}$ throughout the experiments in voltage-clamp mode unless indicated otherwise. Baseline EPSCs or EPSPs were evoked by stimulation of the BLA every $20 \mathrm{~s}$. To minimize the effects of washout in whole-cell recordings, an application of PACAP started within $10 \mathrm{~min}$ after the establishment of wholecell configuration. Off-line data analysis was performed using Clampfit 9 program (Molecular Devices).

Pharmacological reagents. Reagents were prepared as stock solutions in water [GDP$\beta$-S, Rp-cAMPS, autocamtide-2-related inhibitory peptide (AIP), and Pep1-TGL], ethanol (picrotoxin), or DMSO (Xestospongin-C and chelerythrine) at 200- to 2000-fold concentrations, and stored at $-20^{\circ} \mathrm{C}$. Stock solutions of peptides (PACAP38, PACAP6-38, and PG 97269) were prepared in the standard ACSF at the concentration of $0.25 \mathrm{~mm}$ and stored at $-20^{\circ} \mathrm{C}$. Reagents were purchased from Sigma-Aldrich (picrotoxin, GDP- $\beta$-S, and BAPTA), Enzo Life Sciences (Xestospongin-C), and Tocris Biosci-

represent mean values. $\boldsymbol{E}$, Top graph, The time course of EPSP amplitude changes in the presence of $50 \mu \mathrm{M}$ PTX before and after PACAP38 application (red horizontal bar; $n=7$ ). EPSPs were recorded in CeL neurons in current-clamp mode at -70 $\mathrm{mV}$. The bottom graph shows the time course of changes in the resting membrane potential, $\Delta V_{m^{\prime}}$ relative to the pre-PACAP value. The insets show averaged BLA-CeL EPSPs recorded before (black trace) and after (red trace) PACAP38 application. Error bars indicate SEM. 

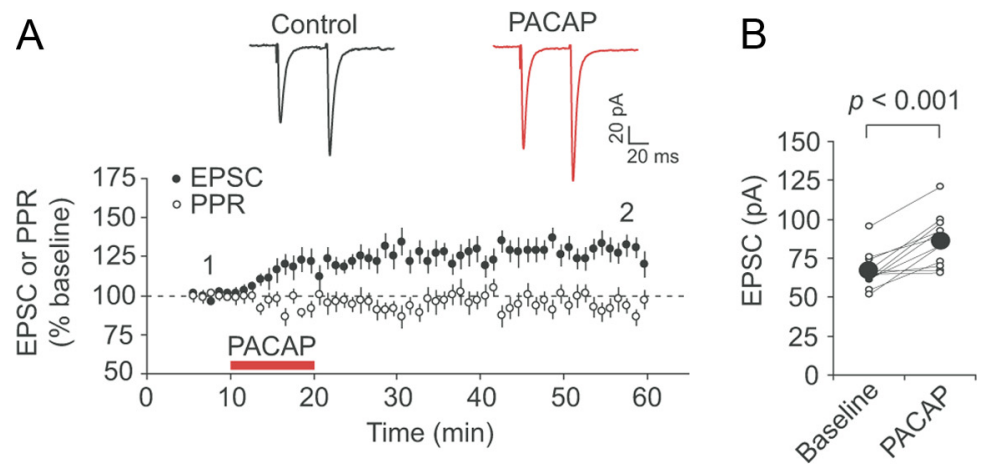

C
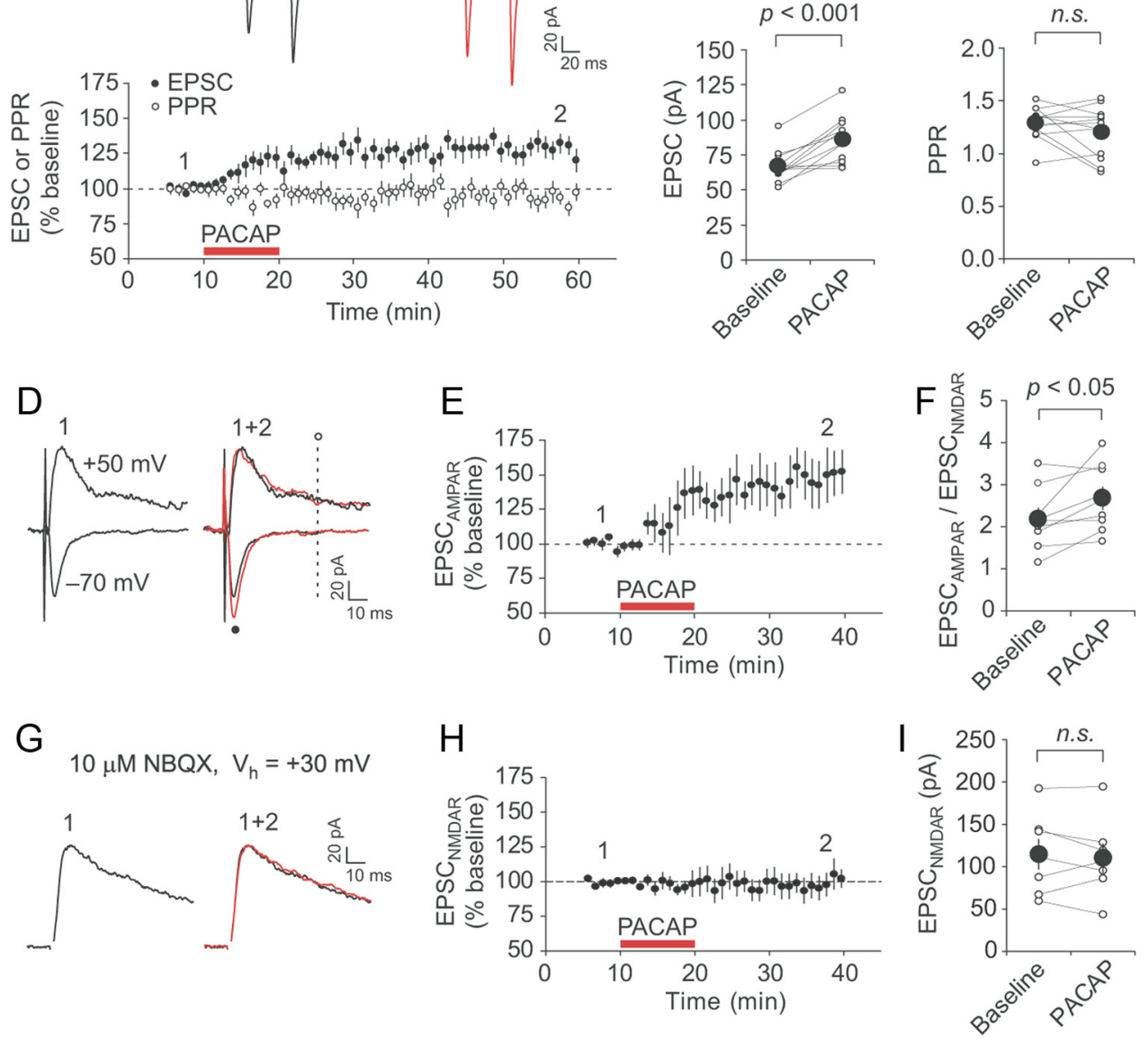

Figure 3. Potentiation of synaptic transmission in the BLA-CeL projections by PACAP implicates postsynaptic expression mechanisms. $\boldsymbol{A}$, Summary graphs demonstrating the time course of EPSC (filled symbols; $n=12$ ) and PPR (open symbols; $n=12$ ) magnitude changes produced by PACAP38 application (red horizontal bar). The EPSCs were recorded at $-70 \mathrm{mV}$ in voltage-clamp mode. The insets show averaged paired BLA-CeL EPSCS (50 ms interpulse interval) obtained before (black trace) and after (red trace) PACAP38 application. $B$, Summary of EPSC amplitude changes induced by PACAP38 for the experiments shown in $\boldsymbol{A}(n=12)$. C, Summary of PPR magnitude changes for the experiments shown in $\boldsymbol{A}(\boldsymbol{n}=12$ ). $\boldsymbol{D}$, Examples of EPSCs (average of $10-15$ traces) recorded at $-70 \mathrm{mV}$ or $+50 \mathrm{mV}$ before (black traces) and after PACAP38 application (red traces) in the presence of PTX (50 $\mu$ M). The amplitude of AMPA receptor-mediated EPSC (EPSC ${ }_{\text {AMPAR }}$ ) was determined at $-70 \mathrm{mV}$ (at a black dot), while the amplitude of NMDA receptor EPSC (EPSC $C_{\text {NMDAR }}$ ) was determined at $+50 \mathrm{mV}$ and measured 50 ms after the stimulus (at a vertical dotted line). $E$, Summary plot

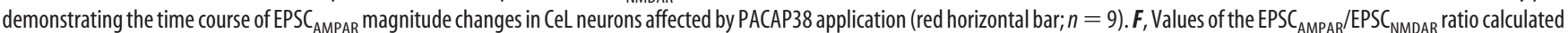
before and after application of PACAP38 $(n=9)$ for the same recordings as in $E$. G, Examples of NMDAREPSCs recorded in CeL neurons at $+30 \mathrm{mV}$ before (black trace) and after (red trace) PACAP38 application. Recordings were performed in the presence of PTX (50 $\mu \mathrm{m})$ and NBQX (10 $\mu \mathrm{m})$. $\boldsymbol{H}$, Time course of EPSC $C_{\text {NMDAR }}$ amplitude changes in response to PACAP application (red horizontal bar; $n=$

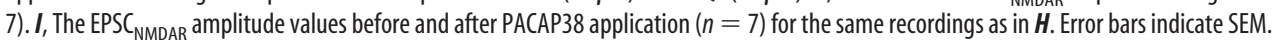

ence (chelerythrine, Rp-cAMPS, and AIP). PACAP38 was purchased from Bachem or Tocris, PACAP6-38 from Bachem or American Peptide Company, PG 97-269 from Phoenix Pharmaceuticals, and Pep1-TGL from Tocris.

Data analysis. The baseline EPSC or EPSP amplitude was calculated by averaging peak amplitudes of responses recorded for 5 min just before the application of PACAP. Peak amplitudes of EPSCs or EPSPs were normalized to the baseline EPSC or EPSP (percentage baseline). Data are presented as mean \pm SEM. In most experiments, peak amplitudes of EPSCs recorded 45-50 min after the onset of PACAP application were averaged and compared with the baseline EPSC. As appropriate, a two-tailed Student $t$ test (paired or unpaired) was used for statistical analyses. Statistical analyses were performed with Minitab 15 software (Minitab), and a value of $p<0.05$ was considered to be statistically significant.

\section{Results}

PACAP-immunoreactive fibers densely innervate the CeL

Consistent with previous reports describing immunohistochemical localization of PACAP in the brain (Piggins et al., 1996; Kozicz and Arimura, 2002), we found that PACAP- immunopositive fibers innervate densely the central nucleus of the amygdala (CeA) (Fig. $1 A, B$ ), whereas PACAP immunoreactivity was not detected in lateral or basolateral nuclei of the amygdala. Specifically, PACAP immunopositive fibers were found predominantly within the lateral division of the central nucleus (CeL). Notably, PACAP-immunopositive fibers formed "collar-like" contacts with neurons in the CeL (Fig. 1C), suggesting that PACAPergic fibers may establish synaptic connections with these cells. These findings support the notion that endogenously released PACAP may affect neuronal functions in the CeL.

\section{PACAP potentiates excitatory synaptic transmission in the BLA-CeL projections}

As PACAP-containing fibers were found predominantly within the $\mathrm{CeL}$, we first examined whether PACAP may affect membrane excitability of CeL neurons. In current-clamp mode, CeL neurons fired action potentials in response to depolarizing current pulses exhibiting spike-frequency adaptation (Fig. 2A). The exogenous applica- 

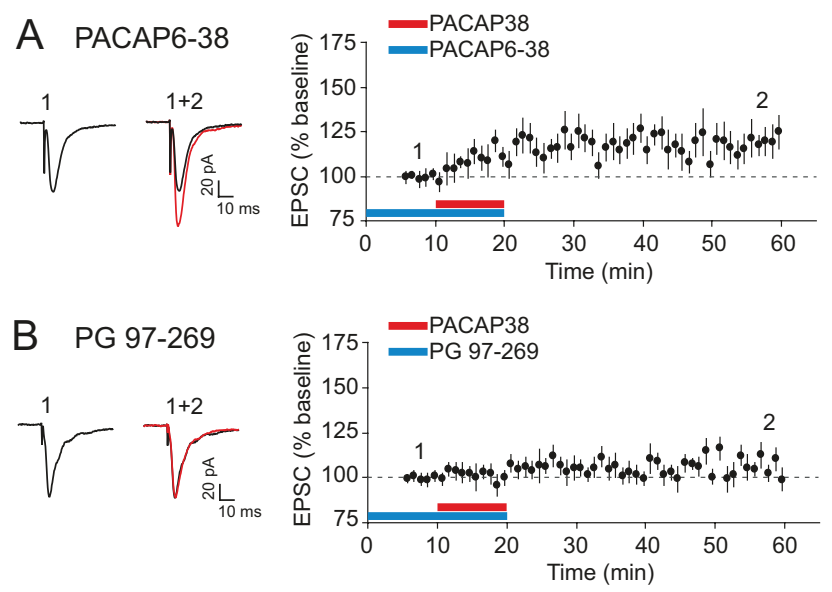

D Anti-sense probe
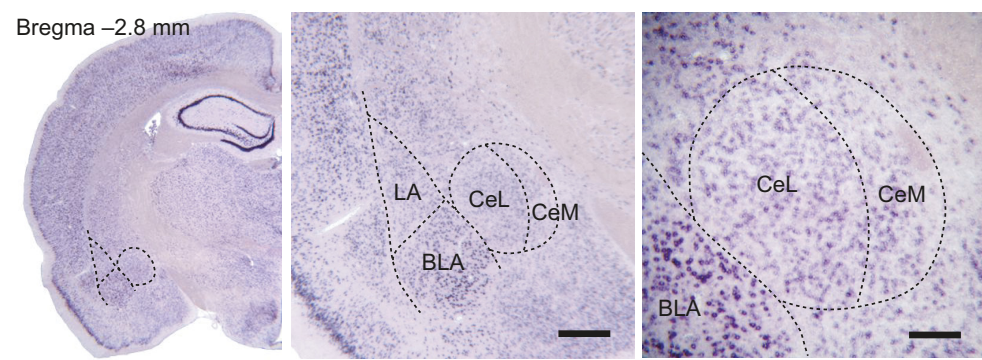

\section{E Sense probe}
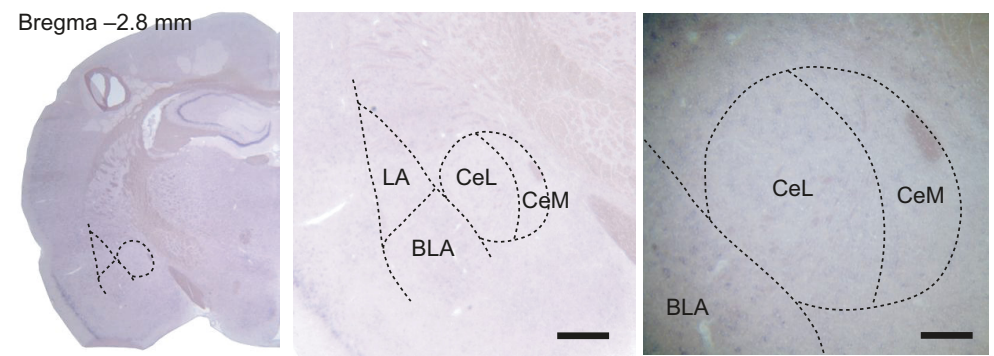

Figure 4. Activation of VPAC1 receptors mediates PACAP-induced potentiation at the BLA-CeL synapses. $A$, Left, Examples of BLA-CeL EPSCs recorded before (black trace) and after (red trace) application of PACAP38 (red horizontal bar) at $-70 \mathrm{mV}$ in the presence of PACAP6-38 (250 nM) in the external medium. Right, Summary graph demonstrating the time course of EPSC amplitude changes produced by PACAP38 (red horizontal bar) in the presence of PACAP6-38 $(n=11)$. The period of antagonist application is shown by a blue horizontal bar. $\boldsymbol{B}$, Same as in $\boldsymbol{A}$ but the experiments were performed in the presence of PG $97-269$ ( $250 \mathrm{~nm}$; blue bar) in the external solution $(n=10)$. C, Summary of EPSC amplitude changes produced by PACAP38 application in the presence of PACAP6-38 ( $n=11$ ) or PG 97-269 ( $n=10)$. Error bars indicate SEM. D, E, RNA in situ hybridization with antisense (D) and sense probes $(\boldsymbol{E})$ demonstrates expression of VPACR1 in the rat brain (purple). Low-magnification images in the left column show the general pattern of VPAC1R expression in coronal brain sections. Higher magnification images in the middle and right columns demonstrate VPAC1Rexpression in the lateral (LA), basolateral (BLA), and central nuclei (lateral division, CeL; medial division, (eM) of the amygdala. The dotted lines indicate borders of the different amygdaloid nuclei. Scale bars: middle, $400 \mu \mathrm{m}$; right, $200 \mu \mathrm{m}$.

tion of PACAP38 (5 nM; $10 \mathrm{~min}$ ), a biologically active and evolutionarily conserved form of endogenously released PACAP (Ishihara et al., 1992; Hashimoto et al., 1993, 2001; Lutz et al., 1993), had no effect on the number of spikes in recorded cells, indicating that firing properties of $\mathrm{CeL}$ neurons were unaffected under these conditions (Fig. $2 A ; n=6$; two-way ANOVA, $p=0.98$ ).

Recent studies, using optogenetics techniques, indicate that the BLA-CeL projections may contribute to the expression of innate fear (Tye et al., 2011; Knobloch et al., 2012). To explore whether PACAP, which is known to produce anxiety-like behaviors (Legradi et al., 2007; Hammack et al., 2010), may modulate neurotransmission in the components of innate fear circuitry, we examined the effects of PACAP on synaptic transmission in the

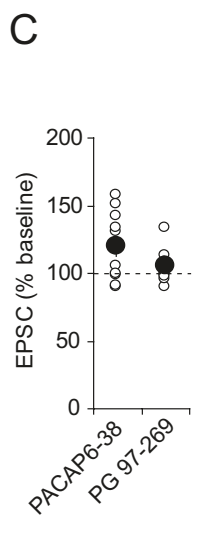

pathway from the BLA to the CeL, densely innervated by PACAP-positive terminals (Fig. 1). Synaptic responses in the CeL neurons were induced by stimulating the BLA (Fig. $2 B$ ), which, in the absence of the GABA receptor $A\left(G_{A B A} R\right)$ antagonist PTX, evoked biphasic postsynaptic potentials in a fraction of the recorded neurons (5 of 10 neurons tested exhibited biphasic responses) under current-clamp conditions at the membrane potential of -55 $\mathrm{mV}$ (Fig. 2C). The biphasic responses consisted of the initial EPSP, which was followed by the PTX-sensitive $\mathrm{GABA}_{\mathrm{A}} \mathrm{R}$ mediated IPSP (Fig. 2C,E). The latter was likely reflecting feedforward inhibition of CeL neurons by intercalated cells (Royer et al., 1999; Amano et al., 2010). The AMPA receptor-mediated EPSP, as evidenced by its sensitivity to the specific AMPAR antagonist NBQX $(10 \mu \mathrm{M})$ (data not shown), had a short and constant synaptic delay indicating that the EPSP was monosynaptic in nature (Tsvetkov et al., 2002). After recording stable baseline responses for $5 \mathrm{~min}$, we perfused slices with the ACSF containing $5 \mathrm{~nm}$ PACAP38 for $10 \mathrm{~min}$. The peak amplitude of the EPSP was increased to $131 \pm$ $9 \%$ of its baseline value $35-40$ min after the start of PACAP38 application (Fig. $2 C$, top graph; $D ; n=10$; paired $t$ test, $p<0.01$ vs baseline), whereas the amplitude of IPSP, observed in the EPSP/ IPSP sequences, was unaffected by PACAP38, remaining at $92 \pm 10 \%$ of the baseline value (Fig. $2 C$, bottom graph; $D ; n=5$; $p=0.49$ ). Notably, the EPSPs remained potentiated even after the washout of PACAP38 for $>30 \mathrm{~min}$. We also examined the action of PACAP38 on isolated BLACeL EPSPs in the presence of $50 \mu \mathrm{M}$ PTX, blocking disynaptic $\mathrm{GABA}_{\mathrm{A}} \mathrm{R}$-mediated IPSPs, at resting membrane potential (approximately $-70 \mathrm{mV}$ ). In these experiments, the duration of exogenous PACAP application was increased to 50 min. The magnitude of PACAP38induced potentiation under these conditions did not differ from that when PACAP38 was applied for a much shorter period of time. Thus, the EPSP amplitude was $148 \pm 16 \%$ of the baseline amplitude after 30 min washout of PACAP38, which was preceded by 50 -min-long PACAP38 application (Fig. $2 E ; n=7$; paired $t$ test, $p<0.05$ vs baseline; not significantly different from the peak EPSP amplitude following 10-min-long application of PACAP38 followed by 30 min washout, $t$ test, $p=$ 0.38 ). The observed synaptic enhancements were not associated with changes in the resting membrane potential in the course of prolonged application of PACAP38 (Fig. 2 E, bottom graph). These findings indicate that PACAP may induce selective and lasting potentiation of neurotransmission at excitatory glutamatergic synapses in the BLA-CeL projections. 
PACAP-induced potentiation of excitatory transmission at the BLA-CeL synapses is postsynaptically expressed

PACAP could facilitate excitatory synaptic transmission either by increasing the probability of release from presynaptic BLA terminals or enhancing the responsiveness of postsynaptic CeL neurons to the unchanged amount of glutamate (Regehr and Stevens, 2001). To distinguish between these alternative possibilities, we recorded EPSCs in CeL neurons under voltage-clamp conditions at a holding potential of $-70 \mathrm{mV}$ in the presence of $50 \mu \mathrm{M}$ PTX in external medium. As in the above-described experiments, synaptic responses were evoked by stimulation electrodes placed in the BLA. Similar to the effects of PACAP38 on the EPSP (Fig. 2C,E), addition of PACAP38 to the ACSF produced a progressive increase in the peak amplitude of the EPSC (Fig. 3A). The magnitude of the EPSC remained elevated to $130 \pm 6 \%$ of its baseline value even after the washout of PACAP38 for 35-40 min (Fig. $3 A, B ; n=12$; paired $t$ test, $p<$ 0.001 vs baseline).

To explore the synaptic site of PACAP38-induced potentiation, we first tested the effects of exogenous PACAP38 on pairedpulse ratio (PPR) (50 ms interval), which is inversely related to the presynaptic release probability, and, therefore, changes in PPR reflect presynaptic modifications (Zucker and Regehr, 2002). We found that potentiation of synaptic transmission following PACAP38 application was not associated with changes in the PPR magnitude (Fig. 3A, $C$; PPR magnitude was $1.28 \pm 0.05$ and $1.20 \pm$ 0.07 before and after PACAP38 application, respectively; $n=12$; paired $t$ test, $p=0.21$ ), indicating that PACAP38 had no effect on the probability of release at the BLA-CeL synapses. To examine further the expression mechanism of PACAP-induced potentiation, we obtained and compared the $\mathrm{EPSC}_{\mathrm{AMPAR}} / \mathrm{EPSC}_{\mathrm{NMDAR}}$ ratio, as a measure of changes in the postsynaptic sensitivity to glutamate, before and after PACAP38 application. The NMDA receptormediated component of the EPSC was determined at $+50 \mathrm{mV}$, to relieve the voltage-dependent block of the NMDAR channels by external $\mathrm{Mg}^{2+}$, and measured $50 \mathrm{~ms}$ after the stimulus, while the peak amplitude of the AMPA receptor EPSC was determined at $-70 \mathrm{mV}$ (Fig. 3D). The EPSC $\mathrm{AMMAR}_{\mathrm{AR}}$ was significantly potentiated by $10 \mathrm{~min}$ application of $5 \mathrm{~nm} \mathrm{PACAP38} \mathrm{(Fig.} 3 E ; n=9$; paired $t$ test, $p<0.05$ vs baseline). However, the amplitude of $\mathrm{EPSC}_{\mathrm{N}^{-}}$ MDAR did not change significantly in these neurons after the addition of PACAP38 $\left(n=9\right.$; EPSC $_{\text {NMDAR }}$ was $32 \pm 4$ and $37 \pm 5$ pA before and after PACAP38 application, respectively; paired $t$ test, $p=0.31$ ). Consistent with these results, the $\mathrm{EPSC}_{\mathrm{AMPAR}} /$ EPSC $_{\text {NMDAR }}$ ratio increased significantly after PACAP38 application (Fig. $3 F ; n=9$; paired $t$ test, $p<0.05$ ), supporting the notion that the application of PACAP led to a selective increase in the EPSC $_{\text {AMPAR }}$ amplitude, while the EPSC $_{\text {NMDAR }}$ remained unchanged.

We also tested the effect of PACAP on isolated NMDAR EPSCs, performing recordings from CeL neurons at $+30 \mathrm{mV}$ in the presence of the AMPA receptor antagonist NBQX $(10 \mu \mathrm{M})$ and PTX $(50 \mu \mathrm{M})$. We found that PACAP ( $5 \mathrm{nM})$ had no effect on the amplitude of NMDAR EPSCs over the course of recordings (Fig. $3 G-I$ ), with the amplitude remaining at $98 \pm 8 \%$ of the baseline value (Fig. $3 G-I ; n=7$; paired $t$ test, $p=0.85$ vs baseline) 25-30 min after the start of PACAP application. Together, these findings demonstrate that PACAP-induced potentiation at the BLA-CeL synapses is associated with increased postsynaptic responsiveness of CeL neurons to glutamate released from the BLA terminals and thus is postsynaptically expressed.
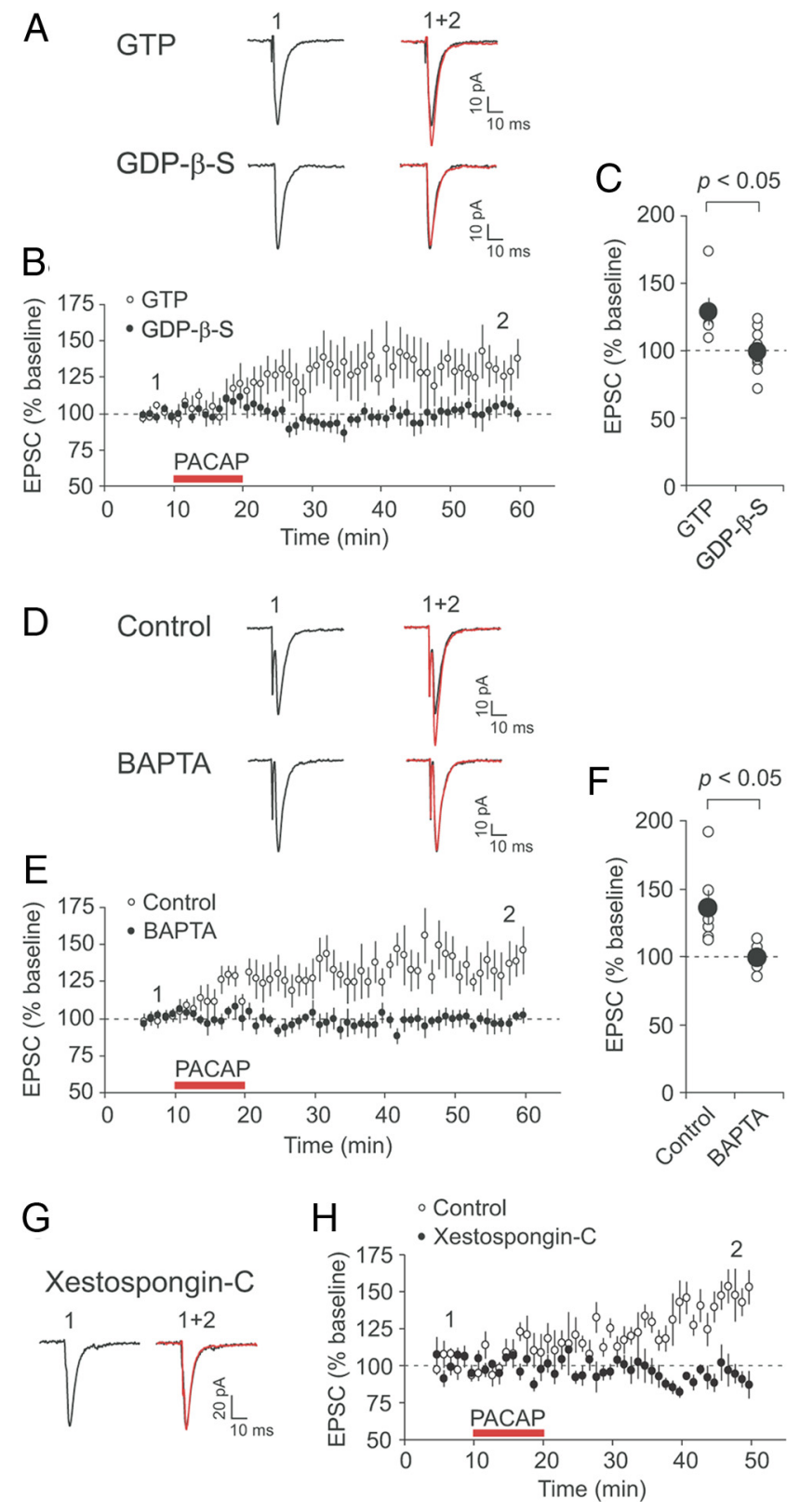

Figure 5. G-protein-coupled signaling and rise in intracellular $\mathrm{Ca}^{2+}$ concentration are required for PACAP-induced potentiation. $\boldsymbol{A}$, Examples of EPSCs recorded in CeL neurons before (black traces) and after PACAP38 application (red traces) when pipette solution contained either GTP (top traces) or GDP- $\beta$-S ( $1 \mathrm{~mm}$; bottom traces). EPSCs were evoked by stimulation of the BLA every $20 \mathrm{~s}$ and recorded at $-70 \mathrm{mV}$. $\boldsymbol{B}$, Time course of EPSC amplitude changes produced by PACAP38 (red horizontal bar) in the presence of GTP ( $n=6$; open circles) or GDP- $\beta$-S ( $n=9$; filled circles) in recording pipette solution. C, Summary of the EPSP amplitude changes after PACAP38 application for the experiments shown in $\boldsymbol{B}$ ( $n=6$ and $n=9$ for the experiments with GTP or GDP- $\beta$-S, respectively). D, Examples of EPSCs recorded before (black traces) and after PACAP38 application (red traces) under control conditions ( $0.2 \mathrm{~mm}$ EGTA in pipette solution; top traces) and in the presence of $10 \mathrm{~mm}$ BAPTA in pipette solution (bottom traces). $\boldsymbol{E}$, Time course of EPSC amplitude changes produced by PACAP38 (red horizontal bar) in CeL neurons loaded with either $0.2 \mathrm{~mm} \mathrm{EGTA} \mathrm{(} n=6$; open circles) or $10 \mathrm{~mm} \mathrm{BAPTA} \mathrm{(} n=8$; filled circles). $\boldsymbol{F}$, Summary of the EPSP amplitude changes after PACAP38 application for the experiments shown in $\boldsymbol{E}(n=6$ for EGTA; $n=8$ for BAPTA). G, EPSCs recorded before (black trace) and after PACAP38 application (red trace) when CeL neurons were loaded with $2.5 \mu \mathrm{m}$ Xestospongin-C. $\boldsymbol{H}$, Time course of EPSC amplitude changes produced by PACAP in CeL neurons either loaded with Xestospongin-C ( $n=6$; filled circles) or under control conditions ( $n=7$; open circles). Error bars indicate SEM. 

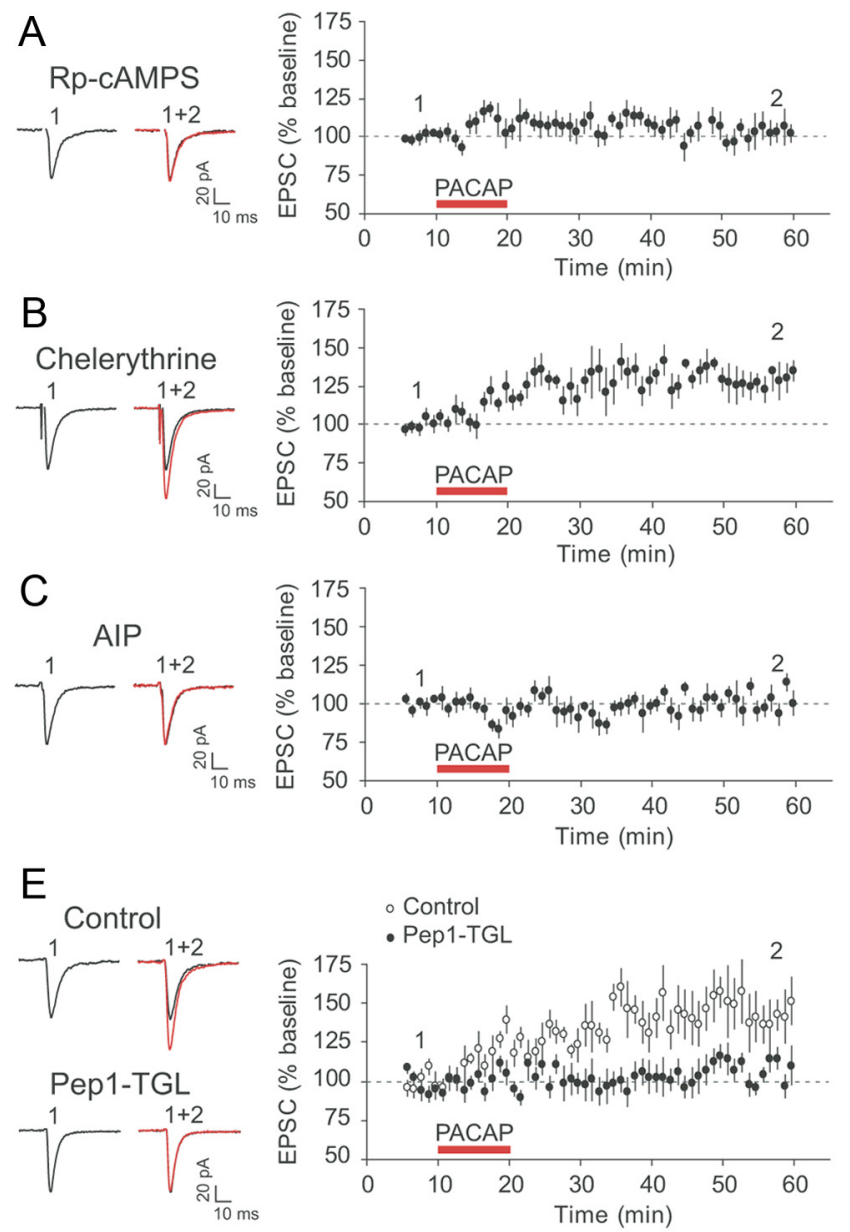

Figure 6. Postsynaptic mechanism of PACAP38-induced synaptic potentiation in CeL neurons. $\boldsymbol{A}$, Left, Examples of EPSCS recorded in (eL neurons before (black trace) and after PACAP38 application (red trace) when pipette solution contained the CAMP antagonist Rp-CAMPS (100 $\mu \mathrm{M}$ ). Right, Time course of EPSC amplitude changes produced by PACAP38 (red horizontal bar) in CeL neurons loaded with Rp-cAMPS $(n=7)$. $B$, Effects of PACAP38 were tested in the presence of PKC inhibitor chelerythrine (10 $\mu \mathrm{M}$ in external solution) ( $n=7)$. C, Effects of PACAP38 were tested in CeL neurons loaded with CaMKII inhibitor AIP $(5 \mu \mathrm{m} ; n=6)$. $\boldsymbol{D}$, Summary of the EPSP amplitude changes after PACAP38 application for the experiments shown in $A-C(n=7$ for the experiments with Rp-cAMPS; $n=7$ for chelerythrine; $n=6$ for AIP). $E$, Left, Examples of EPS(s recorded in CeL neurons before (black traces) and after PACAP38 application (red traces) under control conditions and when pipette solution contained Pep1-TGL $(200 \mu \mathrm{M})$. Loading postsynaptic CeL neurons with Pep1-TGL blocked synaptic potentiation by PACAP38. This indicates that synaptic targeting of GluR1 subunit-containing AMPA receptors was necessary for PACAP-induced potentiation in CeL neurons. Right, Time course of EPSC amplitude changes produced by PACAP38 (red horizontal bar) in CeL neurons. $F$, Summary of the EPSP amplitude changes produced by PACAP38 application under control conditions and in the presence of Pep1-TGL in pipette solution (control, $n=5$; Pep1-TGL, $n=9$ ). Error bars indicate SEM.

\section{Potentiating effect of PACAP at the BLA-CeL synapses is mediated by activation of VPAC1 receptors}

PACAP exerts its physiological functions through binding to two different receptor subtypes: type I receptor (PAC1), which is a specific receptor for endogenous PACAP, and type II receptors, VPAC1 and VPAC2, which could be activated by both PACAP and VIP (Ishihara et al., 1992; Hashimoto et al., 1993; Lutz et al., 1993). To identify the receptor subtype mediating the observed potentiation at the BLA-CeL synapses, we first tested the effects of PACAP38 (5 nM) in the presence of PACAP6-38 (250 nM), known to block both PAC1 and VPAC2 receptors (Robberecht et al., 1992; Fizanne et al., 2004), but not VPAC1 receptors when used in this concentration (Dickinson et al., 1997). Under these conditions, PACAP38 application still resulted in potentiation of EPSCs in CeL neurons to $120 \pm 7 \%$ of the baseline value (Fig. $4 A$; $n=11$; paired $t$ test, $p<0.05$ vs baseline). There was no signifi-

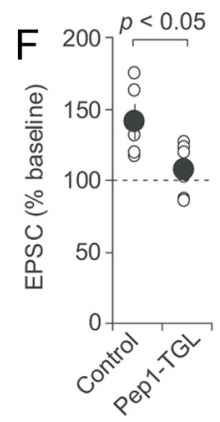

cant difference in PACAP-induced potentiation of the EPSC amplitude between control (as shown in Fig. $3 A, B$ ) and PACAP6-38-treated slices (unpaired $t$ test, $p=0.31$ ). However, a selective VPAC1 receptor antagonist, PG 97-269 (250 nM) (Gourlet et al., 1997), prevented potentiation at the BLA-CeL synapses by PACAP38, as the EPSC amplitude remained at $105 \pm 4 \%$ of its baseline value (Fig. $4 B, C ; n=10$; paired $t$ test, $p=0.18$ vs baseline). Importantly, PG 97-269 has a very low affinity for PAC1 and VPAC2 receptors in a concentration used (Gourlet et al., 1997; Dickson et al., 2006).

We also analyzed the expression pattern of the VPAC1R gene in the amygdala by mRNA in situ hybridization (Fig. $4 D, E) . V P A C 1 R$ mRNA was present in different amygdaloid nuclei, including the CeL (Fig. 4D), which is densely innervated by the PACAP-containing fibers (Fig. 1A,B), thus confirming previous reports (for review, see Vaudry et al., 2009). These results suggest that PACAP38induced potentiation in projections from the BLA to the CeL could be mediated by VPAC1 receptors.

\section{Signal transduction mechanisms underlying PACAP-induced synaptic enhancements in the CeL}

The findings that PACAP38-induced potentiation of the BLA-CeL EPSC is postsynaptically expressed and mediated by VPAC1 receptor, which is G-proteincoupled (Vaudry et al., 2009), suggest that the potentiating action of PACAP38 may occur via activation of the G-protein-mediated signaling pathways in postsynaptic CeL neurons. Consistent with this notion, we found that loading postsynaptic CeL neurons with a nonphosphorylatable analog of GDP, GDP- $\beta$-S ( $1 \mathrm{~mm})$, which inhibits the function of G-proteins, prevented potentiation of the BLA-CeL EPSCs by PACAP38, with the EPSC amplitude remaining at $99 \pm 5 \%$ of the baseline EPSC value (Fig. $5 A-C ; n=9$; paired $t$ test, $p=0.91$ vs baseline). However, the EPSC amplitude was potentiated to $129 \pm 9 \%$ of its baseline value $(n=6$; paired $t$ test, $p<0.05)$ following PACAP38 application when the recording pipette solution contained GTP. This indicates that activation of postsynaptic G-protein-coupled signaling mechanisms is implicated in PACAP38-induced potentiation of glutamatergic synaptic transmission in the BLA-CeL projections.

Binding of PACAP to VPAC1 receptor results in activation of $\mathrm{G}_{\alpha s}$-protein leading to the increased production of the cAMP and stimulation of the cAMP/PKA signaling pathway (Sreedharan et al., 1994; Dickson et al., 2006; Yang et al., 2010). VPAC1 receptor was also shown to be coupled to $G_{\alpha q}$-protein stimulating the inositol 1,4,5-trisphosphate $\left(\mathrm{InsP}_{3}\right) / \mathrm{Ca}^{2+}$-dependent intracellular mechanisms (Langer and Robberecht, 2005; Dickson and Fin- 
A
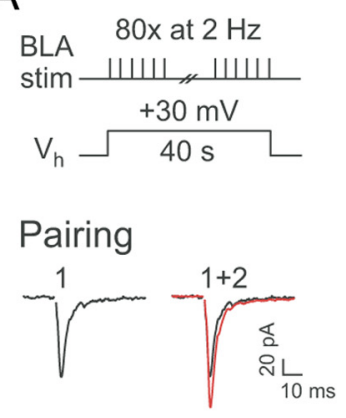

PACAP + pairing

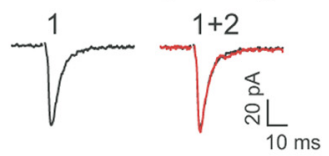

B
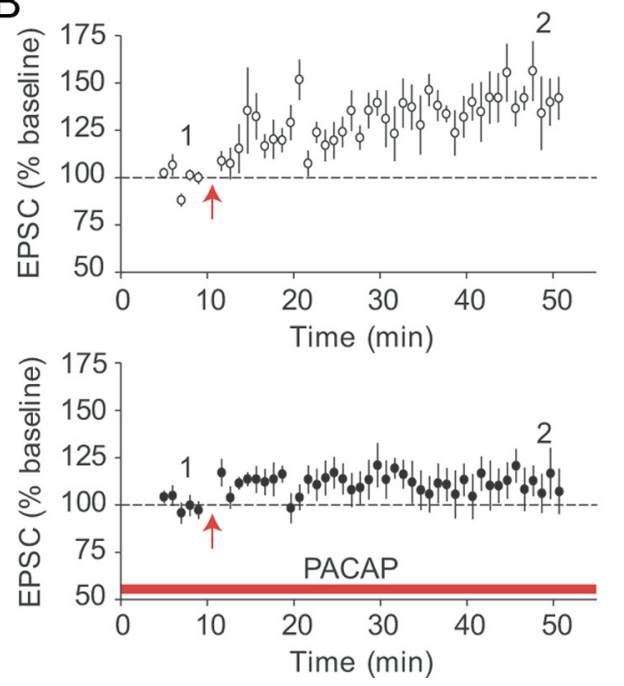

C

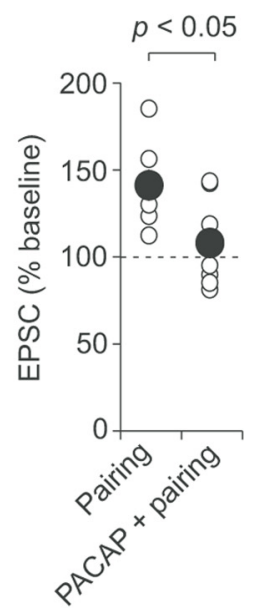

Figure 7. Pairing-induced LTP in the BLA-CeL pathway is occluded in slices treated with PACAP. A, A diagram illustrating a pairing protocol that was used for the induction of LTP (top). Below, EPSCs recorded in CeL neurons before (black traces) and 35-40 min after (red traces) the delivery of LTP-inducing stimulation either under control conditions (Pairing) or in the presence of $5 \mathrm{~nm}$ PACAP (PACAP + pairing). Recordings were performed in the presence of $50 \mu \mathrm{m}$ PTX. $B$, Top, Summary graph of LTP experiments performed in control external solution ( $n=7)$. LTP was induced at the red arrow. Bottom, Summary graph of LTP experiments performed on PACAP38-treated slices $(n=8)$. The red horizontal bar indicates the duration of PACAP38 application ( $5 \mathrm{nM})$, which started $>10$ min before the establishing of whole-cell configuration. C, Summary plot of the EPSC amplitude changes after the delivery of pairing protocol with (PACAP + pairing) or without PACAP pretreatment (Pairing). Error bars indicate SEM.

layson, 2009). Thus, it has been demonstrated previously in heterologous expression systems that activation of VPAC1 receptors may lead to the increase in intracellular $\mathrm{Ca}^{2+}$ concentration (Sreedharan et al., 1994). To determine whether the potentiating action of PACAP38 on synaptic transmission in the amygdala may depend on the rise of $\mathrm{Ca}^{2+}$ concentration in postsynaptic CeL neurons, we included a high concentration of the fast $\mathrm{Ca}^{2+}$ chelator BAPTA (10 mM) in the recording pipette solution. Under these conditions, PACAP38-induced potentiation was suppressed, with the EPSC amplitude remaining at $99 \pm 3 \%$ of the baseline value 35-40 min after the end of PACAP38 application (Fig. $5 D-F ; n=8$; paired $t$ test, $p=0.78$ vs baseline). PACAP38 retained, however, its ability to potentiate the BLA-CeL EPSCs when the recording pipette solution contained $0.2 \mathrm{mM}$ EGTA, a low-affinity $\mathrm{Ca}^{2+}$ chelator not preventing increases in intracellular $\mathrm{Ca}^{2+}$ when used in a given concentration. The EPSC was potentiated by PACAP38 in these experiments to $136 \pm 12 \%$ of the baseline amplitude $(n=6$; paired $t$ test, $p<0.05)$. Therefore, an increase in postsynaptic $\mathrm{Ca}^{2+}$ concentration is required for potentiation of synaptic transmission at the BLA-CeL synapses by PACAP38.

Moreover, we investigated the source of postsynaptic $\mathrm{Ca}^{2+}$ necessary for the potentiating effect of PACAP38. As VPAC1 receptor is $\mathrm{G}_{\alpha \mathrm{q}}$-coupled and may activate phospholipase $\mathrm{C}$ (Langer and Robberecht, 2005), the effects of PACAP on synaptic transmission in the amygdala could be mediated by release of $\mathrm{Ca}^{2+}$ from the internal $\mathrm{Ca}^{2+}$ stores. Consistent with this notion, potentiation of the BLA-CeL EPSCs by PACAP38 was blocked when Xestospongin-C $(2.5 \mu \mathrm{M})$, an inhibitor of $\mathrm{InsP}_{3}$ receptors (Gafni et al., 1997), was included in the recording pipette solution (Fig. 5G,H). Under these experimental conditions, the EPSC amplitude was $96 \pm 8 \%$ of its baseline value following PACAP38 application ( $n=6$; paired $t$ test, $p=0.61$ vs baseline), whereas the EPSC was potentiated by PACAP38 to $149 \pm 9 \%$ of the baseline amplitude $(n=7 ; p<0.01)$ in the absence of Xestospongin- $\mathrm{C}$ in pipette solution. This indicates that $\mathrm{Ca}^{2+}$ release from the $\mathrm{InsP}_{3}$ sensitive $\mathrm{Ca}^{2+}$ stores may contribute to the PACAP38-induced potentiation at synaptic inputs to CeL neurons formed by projections originating in the BLA.

To investigate further the signaling mechanisms lying downstream of the VPAC1 receptor activation, we dialyzed recorded CeL neurons with pipette solution containing specific protein kinase inhibitors. First, we examined whether the potentiating effect of PACAP on the BLA-CeL EPSCs depended on activation of protein kinase A (PKA) by loading CeL neurons with Rp-cAMPS (100 $\mu \mathrm{M})$, a competitive inhibitor of the CAMP-induced activation of PKA (Van Haastert et al., 1984). The intracellular introduction of RpcAMPS resulted in a complete block of synaptic potentiation by PACAP38, with the EPSC amplitude remaining at $106 \pm 6 \%$ of the baseline value (Fig. $6 A, D ; n=7$; paired $t$ test, $p=0.38$ ), suggesting that activation of the $\mathrm{CAMP} / \mathrm{PKA}$ pathways might be required for the PACAP effect on synaptic transmission.

As VPAC1 receptor is coupled to the $\mathrm{G}_{\alpha \mathrm{q}}$-protein, which is capable of activating phospholipase C (Langer and Robberecht, 2005), and our results indicate that the PACAP-induced potentiation at the BLA-CeL synapses depended on the rise in postsynaptic $\mathrm{Ca}^{2+}$ concentration, we next asked whether activation of protein kinase $\mathrm{C}(\mathrm{PKC})$ by postsynaptic $\mathrm{Ca}^{2+}$ may contribute to the observed effects of PACAP on synaptic function in CeL neurons. We found, however, that an addition of chelerythrine (10 $\mu \mathrm{M}$ ), a specific cell-permeable PKC antagonist (Herbert et al., 1990), to the external solution did not suppress the ability of PACAP38 to potentiate synaptic transmission in the BLA-CeL pathway. Thus, the EPSC amplitude was potentiated by PACAP38 to $130 \pm 8 \%$ of the baseline value (Fig. $6 B, D ; n=7$; paired $t$ test, $p<0.05$ ), which was not significantly different from potentiation under control conditions (as shown in Fig. $3 A, B ; t$ test, $p=0.99$ between experimental groups). This finding indicates that PACAP-induced synaptic enhancements in the CeL do not require activation of PKC. However, the dialysis of CeL neurons with intrapipette solution containing AIP $(5 \mu \mathrm{M})$, which blocks $\mathrm{Ca}^{2+} /$ calmodulin-dependent protein kinase II (CaMKII) (Ishida et al., 1995), suppressed PACAP38-induced potentiation. The amplitude of the BLA-CeL EPSC was $103 \pm 3 \%$ of the base- 
A Cell-attached

Whole-cell current clamp
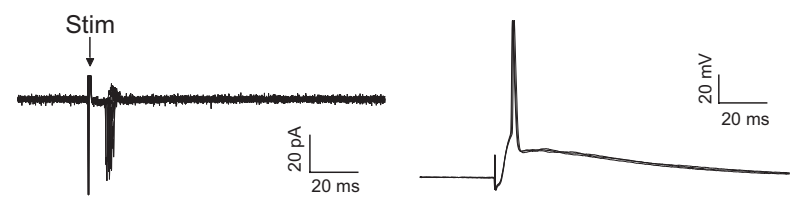

B

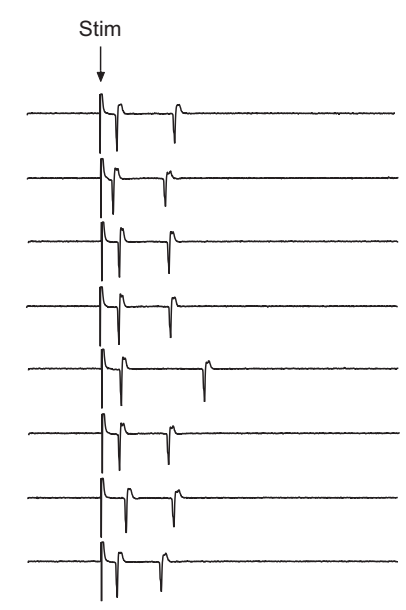

\section{PACAP}

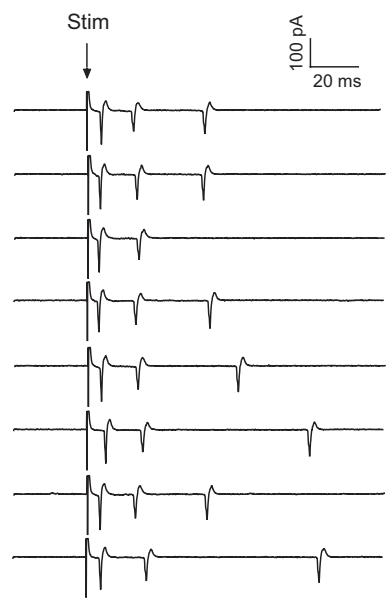

C

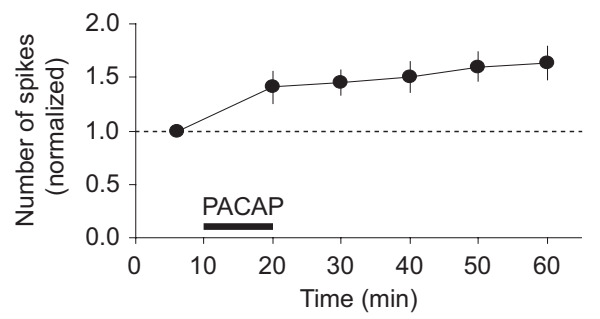

Figure 8. PACAP38 increases synaptically driven firing output of CeL neurons during activation of the BLA.A, Left, Superimposed extracellular spikes evoked in a CeL neuron by stimulation of the BLA and recorded in a cell-attached patch configuration (left) [as in the study by Riccio et al. (2009)]. Right, Recordings from the same neuron under current-clamp conditions after a whole-cell recording configuration was established. In given examples, 10 traces in cellattached configuration and 3 traces in whole-cell current-clamp mode were superimposed. $\boldsymbol{B}$, Left, Examples of responses in the CeL neuron in the course of BLA stimulation (once every 10 $\mathrm{min}$ ) by electrical pulses of the constant intensity under control conditions. Right, Spike firing output of the same CeL neuron $40 \mathrm{~min}$ after the start of PACAP38 application ( $5 \mathrm{~nm} ; 10 \mathrm{~min}$ ). $C$, Time course of changes in firing output of CeL neurons produced by PACAP38 application (horizontal bar) $(n=6)$. Firing output was quantified as the average number of spikes per stimulus (the total number of spikes divided by the number of stimuli), which was then normalized to its baseline pre-PACAP value (marked with a horizontal dotted line). Error bars indicate SEM.

line value 35-40 min after the end of PACAP38 application (Fig. $6 C, D ; n=6$; paired $t$ test, $p=0.41$ ), showing that activation of postsynaptic CaMKII kinase might be required for the effect of PACAP38 on synaptic function. Thus, both cAMP/PKA pathway and CaMKII-dependent signaling in postsynaptic CeL neurons are implicated in potentiation of neurotransmission in the BLA-CeL pathway by PACAP38.

\section{Enhanced synaptic targeting of GluR1 subunit-containing AMPA receptors may underlie PACAP-induced potentiation}

The involvement of postsynaptic signaling mechanisms in synaptic effects of PACAP, as well as postsynaptic expression of
PACAP38-induced potentiation (Fig. $3 A, C$ ), suggested to us that postsynaptic trafficking of GluR1 subunit-containing AMPA receptor to the sites of synaptic transmission could contribute to PACAP-induced synaptic strengthening (Hayashi et al., 2000). To explore this possibility, we loaded postsynaptic CeL neurons with Pep1-TGL $(200 \mu \mathrm{M})$, a synthetic peptide which corresponds to the $\mathrm{C}$ terminus of the AMPA receptor GluR1 subunit and inhibits the delivery of GluR1-containing AMPA receptors to the postsynaptic sites by disrupting the interaction of GluR1 C terminus with the synapse-associated protein SAP97 (Hayashi et al., 2000; Shi et al., 2001; Yang et al., 2008; Lin et al., 2010; Polepalli et al., 2010). This experimental intervention resulted in a suppression of PACAP38-induced potentiation, with the EPSC amplitude remaining at $107 \pm 5 \%$ of the baseline value (Fig. $6 E, F ; n=$ 9; paired $t$ test, $p=0.18$ ), whereas in the absence of Pep1-TGL in pipette solution the BLA-CeL EPSC was potentiated to $141 \pm$ $12 \%$ of the baseline amplitude $(n=5 ; p<0.05$ vs baseline; the difference between two experimental groups was highly significant, $t$ test, $p<0.05)$. Thus, PACAP38 could possibly enhance postsynaptic responsiveness to glutamate in CeL neurons by promoting synaptic targeting of GluR1 subunit-containing AMPA receptors.

Furthermore, we examined whether the induction of longterm potentiation (LTP) at the BLA-CeL synapses could be affected by PACAP administration. LTP was readily induced in the studied pathway with the pairing protocol $(80$ pulses $/ 2 \mathrm{~Hz}$ at a holding potential of $+30 \mathrm{mV}$ ) under control conditions $(50 \mu \mathrm{M}$ PTX, no PACAP in the external solution). LTP-inducing stimulation resulted in potentiation of the BLA-CeL EPSCs to $141 \pm$ $9 \%$ of the baseline amplitude value $35-40 \mathrm{~min}$ after the induction (Fig. $7 A-C ; n=7$; paired $t$ test, $p<0.01$ vs baseline). We found that PPR was unaltered following the induction of LTP $(n=7$; paired $t$ test, $p=0.24$ ), suggesting that LTP under these conditions was expressed postsynaptically. Next, we pretreated slices with $5 \mathrm{nM}$ PACAP for $>10 \mathrm{~min}$, and then performed whole-cell patch-clamp recordings from CeL neurons in the continuous presence of PACAP. After the baseline recording (which was of the same duration as in the experiments in control external solution), we attempted to induce LTP by delivering the abovedescribed pairing protocol. Under these conditions, the amplitude of the BLA-CeL EPSC remained at $108 \pm 9 \%$ of the baseline value ( $n=8$; paired $t$ test, $p=0.39$ vs baseline; significantly different from control LTP, unpaired $t$ test, $p<0.05$ ), suggesting that LTP in the studied pathway might be largely occluded by the prior PACAP-induced potentiation. Together with the finding that PACAP-induced potentiation also did not affect the amplitude of PPR (Fig. 3A-C), these results suggest that PACAP-induced potentiation and LTP induced by electrical stimulation may share common postsynaptic mechanisms (e.g., protein kinase pathways and/or synaptic targeting of GluR1containing AMPA receptors).

\section{PACAP increases firing output of CeL neurons in response to} synaptic activation of inputs from the BLA

Finally, we explored the role of synaptic enhancements in the BLA-CeL pathway, produced by PACAP38, in regulation of neuronal functions in the CeL. For this, we tested the effect of PACAP on the number of extracellular spikes evoked in individual CeL neurons by presynaptic stimuli of constant intensity delivered to the BLA (Riccio et al., 2009). The estimates of spiking output of CeL neurons were obtained in a cell-attached recording configuration (Fig. $8 \mathrm{~A}$ ) to minimize the effects of prolonged whole-cell recordings on the intracellular milieu, which could possibly affect 
functional properties of the recorded cells. We found that synaptically induced spike firing in CeL neurons, expressed as the average number of spikes triggered by a single presynaptic stimulus, was significantly facilitated by the application of PACAP38 (Fig. $8 B, C$; $n=6$; paired $t$ test, $p<0.01$ vs pre-PACAP baseline; the estimates of the effect of PACAP on neuronal firing were obtained after its $40 \mathrm{~min}$ washout). These findings indicate that PACAP-induced potentiation of synaptic transmission at the BLA-CeL synapses might be functionally relevant, as it is translated into the enhanced firing output of CeL neurons in response to afferent signals arising from the BLA.

\section{Discussion}

Our results demonstrate that PACAP potentiates glutamatergic synaptic transmission in projections from the BLA to the CeL via activation of $\mathrm{G}_{\alpha \mathrm{s}^{-}}$and $\mathrm{G}_{\alpha \mathrm{q}^{-}}$ coupled postsynaptic VPAC1 receptors. This potentiation was associated with increased postsynaptic responsiveness of $\mathrm{CeL}$ neurons to glutamate, without significant changes in presynaptic function, through the intracellular mechanism that implicated both cAMP/PKA and CaMKII-dependent signaling, thus resulting in increased targeting of GluR1 subunit-containing AMPA receptors to the sites of synaptic transmission (Fig. 9) (Hayashi et al., 2000).

PACAP-containing neurons in the dorsal vagal complex of the brainstem are believed to contribute to ascending innervation of the extended amygdala (Kozicz et al., 1998; Das et al., 2007). PACAP-containing fibers and VPAC1 receptors are highly expressed in the CeL, suggesting that PACAP/VPAC1 pathway might be strategically positioned for modulation of neuronal functions in the CeL under conditions associated with endogenous release of PACAP (e.g., acute and chronic stress or anxietyprovoking situations). Notably, PAC1 receptor, a specific receptor for PACAP, is also expressed in the CeL (Joo et al., 2004). Moreover, it has been demonstrated previously that PACAP binds to these two receptors, PAC1 and VPAC1, with similar affinity (Hashimoto et al., 1993; Ishida et al., 1995). As the potentiating effect of PACAP on synaptic transmission was mediated exclusively by VPAC1 receptors, it is plausible that specific characteristics of the surface distribution and density of different PACAP receptor subtypes in CeL neurons could explain the receptor selectivity of PACAP-induced synaptic potentiation. Additionally, neurons in the $\mathrm{CeL}$ receive both excitatory and inhibitory inputs in the course of BLA activation. The $\mathrm{GABA}_{\mathrm{A}}$ receptor-mediated feedforward inhibition of $\mathrm{CeL}$ neurons is likely provided by GABAergic intercalated cells, residing in small neuronal clusters between the BLA and the central nucleus (Royer et al., 1999). Our observation that the actions of PACAP were specific to glutamatergic synapses on CeL neurons suggests that the ability of PACAP to affect synaptic function might be synapse and cell type specific. As PACAP shares VPAC1 and VPAC2 receptors with VIP $\left(K_{\mathrm{d}} \sim 3 \mathrm{nM}\right)$, a neuropeptide with $68 \%$ sequence homology with PACAP that is also expressed in the

\section{BLA neuron} axon terminal
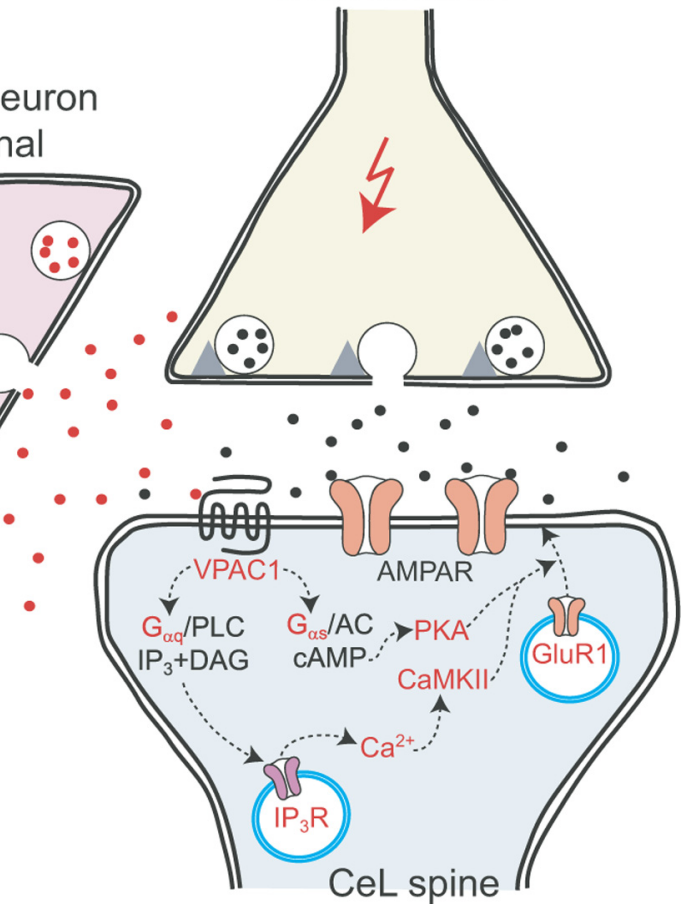

Cel spine

Figure 9. A mechanism for postsynaptically expressed PACAP-induced synaptic enhancements in the BLA-CeL projections. targeting of GluR1 subunit-containing AMPA receptors to the sites of synaptic transmission, thus enhancing the efficacy of glutamatergic synaptic transmission in the BLA-CeL projections.

CeL (Loren et al., 1979; Roberts et al., 1982; Gray et al., 1984; Ishihara et al., 1992), it might be interesting to examine in future studies whether VIP could also affect excitatory synaptic transmission in the BLA to the CeL pathway, possibly acting in concert with PACAP and thus contributing to the amygdala-based behaviors.

Only a handful of earlier studies have addressed the mechanisms of modulatory actions of PACAP at central synapses, mostly in the hippocampus, while synaptic effects of PACAP in the amygdala have not been previously explored. In the hippocampus, the described effects of PACAP on glutamatergic synaptic transmission are somewhat contradictory with some studies reporting that PACAP was inducing long-lasting potentiation at Schaffer collateral-CA1 synapses (Roberto and Brunelli, 2000; Cunha-Reis et al., 2005), whereas other investigators showed that PACAP could depress synaptic responses in the same pathway (Ciranna and Cavallaro, 2003). This experimental divergence could possibly be attributed to the differences in recording conditions and the dosing of PACAP (Roberto et al., 2001). Notably, in a low concentration, PACAP38 (1 nM) was shown previously to increase NMDAR-mediated synaptic currents, both at the Schaffer collateral-CA1 synapses in hippocampal slices and isolated CA1 neurons, via activation of PAC1 receptors, and, subsequently, $G_{\alpha q}$ and PKC (Macdonald et al., 2005). This differs from our findings in the amygdala, where the potentiating effect of PACAP38 was mediated by a different receptor subtype, VPAC1, and limited to the AMPA receptor-mediated synaptic responses, emphasizing the role of regional variations in the expression of receptor subtypes activated by PACAP and their coupling to distinct signaling pathways. 
The observation that PACAP-induced strengthening of glutamatergic synaptic transmission in the BLA-CeL projections could be translated into increased spiking output of neurons in the CeL in response to the BLA-driven synaptic activation is consistent with the demonstrated roles of PACAP in regulation of innate fear responses (Otto et al., 2001b; Legradi et al., 2007). Neuromodulatory functions of PACAP in the CeL appear to be specific to its actions on synaptic transmission, as the membrane properties of CeL neurons were unaffected by this neuropeptide in our experiments. While the neural substrates of innate fear are diffuse and not completely characterized (Shumyatsky et al., 2005; Riccio et al., 2009), it is clear that perturbances in the function of individual components of innate fear circuitry would affect the behavioral outcome.

Recently, several groups independently provided detailed descriptions of microcircuits in the amygdala and their functional roles in connection to the regulation of learned and innate fear responses (Herry et al., 2008; Ciocchi et al., 2010; Haubensak et al., 2010; Tye et al., 2011; Knobloch et al., 2012). Notably, selective activation of the BLA to the CeL pathway was shown to produce an acute anxiolytic effect whereas inhibition of this pathway increased anxiety (Tye et al., 2011), suggesting that CeL neurons may function as an inhibitory gate between the BLA and the medial division of the central nucleus of the amygdala (CeM). Then, if CeL neurons simply inhibit CeM in response to BLA activation, endogenous release of PACAP, which was found to potentiate excitatory transmission in the BLA to the CeL pathway, would be expected to exert anxiolytic effect in vivo. However, functional roles of the CeL in control of information processing within the amygdala might be more complex. Thus, recent studies, combining in vivo electrophysiological recordings and optogenetics, demonstrated that the CeL may contain two different subpopulations of GABAergic neurons $\left(\mathrm{CeL}_{\mathrm{on}} / \mathrm{PKC}-\delta^{-}\right.$ and $\mathrm{CeL}_{\text {off }} / \mathrm{PKC}-\delta^{+}$neurons) (Ciocchi et al., 2010; Haubensak et al., 2010). $\mathrm{CeL}_{\text {on }}$ neurons, which receive inputs from the BLA, display increased firing during presentation of conditioned stimulus. The CeL may disinhibit the CeM through inhibition of $\mathrm{CeL}_{\text {off }}$ neurons by activated $\mathrm{CeL}_{\text {on }}$ neurons. Although $\mathrm{CeL}_{\text {on }}$ neurons also send direct (monosynaptic) inhibitory projection to the $\mathrm{CeM}$, disinhibitory $\mathrm{CeL}_{\text {on }}-\mathrm{CeL}_{\text {off }}-\mathrm{CeM}$ pathway seems to predominate over inhibitory $\mathrm{CeL}_{\mathrm{on}}-\mathrm{CeM}$ pathway (Ciocchi et al., 2010; Haubensak et al., 2010). Based on this model, PACAP would facilitate information flow from the BLA to the CeM if it potentiates excitatory transmission from the BLA to the $\mathrm{CeL}_{\text {on }}$ neurons. Disinhibiting the CeM through decreased activation of $\mathrm{CeL}_{\text {off }}$ neurons would promote fear responses. Our current findings, however, are insufficient to support this model directly, as neurons in the CeL were chosen for recordings randomly. Thus, it may be interesting to explore in future studies whether PACAPergic axon fibers innervate specific populations of CeL neurons ( $\mathrm{CeL}_{\text {on }}$ vs $\mathrm{CeL}_{\text {off }}$ neurons). Double immunohistochemistry for PACAP and PKC $\delta$ could address this question directly. It would also be important to examine whether PACAP could affect neurotransmission in inputs to $\mathrm{CeL}_{\mathrm{on}} / \mathrm{PKC}-\delta^{-}$or $\mathrm{CeL}_{\text {off }} / \mathrm{PKC}-\delta^{+}$ neurons differentially.

While the CeL may function as a relay station, either inhibitory or disinhibitory, between the BLA and the CeM, neurons in the CeL also project to the bed nucleus of the stria terminalis (BNST) (Sun et al., 1991). The BNST and CeA, acting in concert with other brain areas (e.g., the paraventricular nucleus of the hypothalamus), promote anxiety-related behaviors (Hammack et al., 2010). Therefore, modulation of neurotransmission in the BLA-CeL pathway by PACAP, released endogenously in re- sponse to stressful or anxiety-provoking events, may change the activity of both the BNST and CeA, thus affecting anxiety levels. To understand more fully the role of PACAP in regulation of fear responses, it might be necessary to characterize its neuronal and synaptic functions in the components of fear circuitry receiving projections from the amygdala, including the BNST.

\section{References}

Amano T, Unal CT, Paré D (2010) Synaptic correlates of fear extinction in the amygdala. Nat Neurosci 13:489-494.

Basille M, Vaudry D, Coulouarn Y, Jegou S, Lihrmann I, Fournier A, Vaudry H, Gonzalez B (2000) Comparative distribution of pituitary adenylate cyclase-activating polypeptide (PACAP) binding sites and PACAP receptor mRNAs in the rat brain during development. J Comp Neurol 425:495-509.

Cho JH, Bayazitov IT, Meloni EG, Myers KM, Carlezon WA Jr, Zakharenko SS, Bolshakov VY (2012) Coactivation of thalamic and cortical pathways induces input timing-dependent plasticity in amygdala. Nat Neurosci 15:113-122.

Ciocchi S, Herry C, Grenier F, Wolff SB, Letzkus JJ, Vlachos I, Ehrlich I, Sprengel R, Deisseroth K, Stadler MB, Müller C, Lüthi A (2010) Encoding of conditioned fear in central amygdala inhibitory circuits. Nature 468:277-282.

Ciranna L, Cavallaro S (2003) Opposing effects by pituitary adenylate cyclase-activating polypeptide and vasoactive intestinal peptide on hippocampal synaptic transmission. Exp Neurol 184:778-784.

Cunha-Reis D, Ribeiro JA, Sebastião AM (2005) VIP enhances synaptic transmission to hippocampal CA1 pyramidal cells through activation of both VPAC1 and VPAC2 receptors. Brain Res 1049:52-60.

Das M, Vihlen CS, Legradi G (2007) Hypothalamic and brainstem sources of pituitary adenylate cyclase-activating polypeptide nerve fibers innervating the hypothalamic paraventricular nucleus of the rat. J Comp Neurol 500:761-776.

Dickinson T, Fleetwood-Walker SM, Mitchell R, Lutz EM (1997) Evidence for roles of vasoactive intestinal polypeptide (VIP) and pituitary adenylate cyclase activating polypeptide (PACAP) receptors in modulating the responses of rat dorsal horn neurons to sensory inputs. Neuropeptides 31:175-185.

Dickson L, Finlayson K (2009) VPAC and PAC receptors: from ligands to function. Pharmacol Ther 121:294-316.

Dickson L, Aramori I, McCulloch J, Sharkey J, Finlayson K (2006) A systematic comparison of intracellular cyclic AMP and calcium signalling highlights complexities in human VPAC/PAC receptor pharmacology. Neuropharmacology 51:1086-1098.

Fizanne L, Sigaudo-Roussel D, Saumet JL, Fromy B (2004) Evidence for the involvement of VPAC1 and VPAC2 receptors in pressure-induced vasodilatation in rodents. J Physiol 554:519-528.

Gafni J, Munsch JA, Lam TH, Catlin MC, Costa LG, Molinski TF, Pessah IN (1997) Xestospongins: potent membrane permeable blockers of the inositol 1,4,5-trisphosphate receptor. Neuron 19:723-733.

Gourlet P, De Neef P, Cnudde J, Waelbroeck M, Robberecht P (1997) In vitro properties of a high affinity selective antagonist of the VIP1 receptor. Peptides 18:1555-1560.

Gray TS, Cassell MD, Nilaver G, Zimmerman EA, Williams TH (1984) The distribution and ultrastructure of VIP-immunoreactivity in the central nucleus of the rat amygdala. Neuroscience 11:399-408.

Hammack SE, Roman CW, Lezak KR, Kocho-Shellenberg M, Grimmig B, Falls WA, Braas K, May V (2010) Roles for pituitary adenylate cyclaseactivating peptide (PACAP) expression and signaling in the bed nucleus of the stria terminalis (BNST) in mediating the behavioral consequences of chronic stress. J Mol Neurosci 42:327-340.

Hashimoto H, Ishihara T, Shigemoto R, Mori K, Nagata S (1993) Molecular cloning and tissue distribution of a receptor for pituitary adenylate cyclase-activating polypeptide. Neuron 11:333-342.

Hashimoto H, Shintani N, Tanaka K, Mori W, Hirose M, Matsuda T, Sakaue M, Miyazaki J, Niwa H, Tashiro F, Yamamoto K, Koga K, Tomimoto S, Kunugi A, Suetake S, Baba A (2001) Altered psychomotor behaviors in mice lacking pituitary adenylate cyclase-activating polypeptide (PACAP). Proc Natl Acad Sci U S A 98:13355-13360.

Hashimoto H, Shintani N, Baba A (2006) New insights into the central PACApergic system from the phenotypes in PACAP- and PACAP receptor-knockout mice. Ann N Y Acad Sci 1070:75-89. 
Haubensak W, Kunwar PS, Cai H, Ciocchi S, Wall NR, Ponnusamy R, Biag J, Dong HW, Deisseroth K, Callaway EM, Fanselow MS, Lüthi A, Anderson DJ (2010) Genetic dissection of an amygdala microcircuit that gates conditioned fear. Nature 468:270-276.

Hayashi Y, Shi SH, Esteban JA, Piccini A, Poncer JC, Malinow R (2000) Driving AMPA receptors into synapses by LTP and CaMKII: requirement for GluR1 and PDZ domain interaction. Science 287:2262-2267.

Herbert JM, Augereau JM, Gleye J, Maffrand JP (1990) Chelerythrine is a potent and specific inhibitor of protein kinase C. Biochem Biophys Res Commun 172:993-999.

Herry C, Ciocchi S, Senn V, Demmou L, Müller C, Lüthi A (2008) Switching on and off fear by distinct neuronal circuits. Nature 454:600-606.

Hsu SM, Raine L, Fanger H (1981) Use of avidin-biotin-peroxidase complex $(A B C)$ in immunoperoxidase techniques: a comparison between $\mathrm{ABC}$ and unlabeled antibody (PAP) procedures. J Histochem Cytochem 29:577-580.

Ishida A, Kameshita I, Okuno S, Kitani T, Fujisawa H (1995) A novel highly specific and potent inhibitor of calmodulin-dependent protein kinase II. Biochem Biophys Res Commun 212:806-812.

Ishihara T, Shigemoto R, Mori K, Takahashi K, Nagata S (1992) Functional expression and tissue distribution of a novel receptor for vasoactive intestinal polypeptide. Neuron 8:811-819.

Joo KM, Chung YH, Kim MK, Nam RH, Lee BL, Lee KH, Cha CI (2004) Distribution of vasoactive intestinal peptide and pituitary adenylate cyclase-activating polypeptide receptors (VPAC1, VPAC2, and PAC1 receptor) in the rat brain. J Comp Neurol 476:388-413.

Knobloch HS, Charlet A, Hoffmann LC, Eliava M, Khrulev S, Cetin AH, Osten P, Schwarz MK, Seeburg PH, Stoop R, Grinevich V (2012) Evoked axonal oxytocin release in the central amygdala attenuates fear response. Neuron 73:553-566.

Köves K, Arimura A, Görcs TG, Somogyvári-Vigh A (1991) Comparative distribution of immunoreactive pituitary adenylate cyclase activating polypeptide and vasoactive intestinal polypeptide in rat forebrain. Neuroendocrinology 54:159-169.

Kozicz T, Arimura A (2002) Dopamine- and cyclic AMP-regulated phosphoprotein-immunoreactive neurons activated by acute stress are innervated by fiber terminals immunopositive for pituitary adenylate cyclase-activating polypeptide in the extended amygdala in the rat. Regul Pept 109:63-70.

Kozicz T, Vigh S, Arimura A (1998) The source of origin of PACAP- and VIP-immunoreactive fibers in the laterodorsal division of the bed nucleus of the stria terminalis in the rat. Brain Res 810:211-219.

Langer I, Robberecht P (2005) Mutations in the carboxy-terminus of the third intracellular loop of the human recombinant VPAC1 receptor impair VIP-stimulated $\left[\mathrm{Ca}^{2+}\right]_{\mathrm{i}}$ increase but not adenylate cyclase stimulation. Cell Signal 17:17-24.

Legradi G, Das M, Giunta B, Hirani K, Mitchell EA, Diamond DM (2007) Microinfusion of pituitary adenylate cyclase-activating polypeptide into the central nucleus of amygdala of the rat produces a shift from an active to passive mode of coping in the shock-probe fear/defensive burying test. Neural Plast 2007:79102.

Lin MT, Luján R, Watanabe M, Frerking M, Maylie J, Adelman JP (2010) Coupled activity-dependent trafficking of synaptic SK2 channels and AMPA receptors. J Neurosci 30:11726-11734.

Lorén I, Emson PC, Fahrenkrug J, Björklund A, Alumets J, Håkanson R, Sundler F (1979) Distribution of vasoactive intestinal polypeptide in the rat and mouse brain. Neuroscience 4:1953-1976.

Lutz EM, Sheward WJ, West KM, Morrow JA, Fink G, Harmar AJ (1993) The VIP2 receptor: molecular characterisation of a cDNA encoding a novel receptor for vasoactive intestinal peptide. FEBS Lett 334:3-8.

Macdonald DS, Weerapura M, Beazely MA, Martin L, Czerwinski W, Roder JC, Orser BA, MacDonald JF (2005) Modulation of NMDA receptors by pituitary adenylate cyclase activating peptide in CAl neurons requires G $\alpha$ q, protein kinase C, and activation of Src. J Neurosci 25:11374-11384.

Masuo Y, Matsumoto Y, Tokito F, Tsuda M, Fujino M (1993) Effects of vasoactive intestinal polypeptide (VIP) and pituitary adenylate cyclase activating polypeptide (PACAP) on the spontaneous release of acethylcholine from hippocampus by brain microdilaysis. Brain Res 611:207-215.

Miyata A, Arimura A, Dahl RR, Minamino N, Uehara A, Jiang L, Culler MD, Coy DH (1989) Isolation of a novel 38 residue-hypothalamic polypep- tide which stimulates adenylate cyclase in pituitary cells. Biochem Biophys Res Commun 164:567-574.

Nielsen KM, Chaverra M, Hapner SJ, Nelson BR, Todd V, Zigmond RE, Lefcort F (2004) PACAP promotes sensory neuron differentiation: blockade by neurotrophic factors. Mol Cell Neurosci 25:629-641.

Otto C, Kovalchuk Y, Wolfer DP, Gass P, Martin M, Zuschratter W, Gröne HJ, Kellendonk C, Tronche F, Maldonado R, Lipp HP, Konnerth A, Schütz G (2001a) Impairment of mossy fiber long-term potentiation and associative learning in pituitary adenylate cyclase activating polypeptide type I receptor-deficient mice. J Neurosci 21:5520-5527.

Otto C, Martin M, Wolfer DP, Lipp HP, Maldonado R, Schütz G (2001b) Altered emotional behavior in PACAP-type-I-receptor-deficient mice. Brain Res Mol Brain Res 92:78-84.

Pape HC, Pare D (2010) Plastic synaptic networks of the amygdala for the acquisition, expression, and extinction of conditioned fear. Physiol Rev 90:419-463.

Piggins HD, Stamp JA, Burns J, Rusak B, Semba K (1996) Distribution of pituitary adenylate cyclase activating polypeptide (PACAP) immunoreactivity in the hypothalamus and extended amygdala of the rat. J Comp Neurol 376:278-294.

Pisegna JR, Wank SA (1993) Molecular cloning and functional expression of the pituitary adenylate cyclase-activating polypeptide type I receptor. Proc Natl Acad Sci U S A 90:6345-6349.

Polepalli JS, Sullivan RK, Yanagawa Y, Sah P (2010) A specific class of interneuron mediates inhibitory plasticity in the lateral amygdala. J Neurosci 30:14619-14629.

Regehr WG, Stevens CF (2001) Physiology of synaptic transmission and short-term plasticity. In: Synapses (Cowan WM, Südhof TC, Stevens CF, eds), pp 135-175. Baltimore, London: Johns Hopkins UP.

Ressler KJ, Mercer KB, Bradley B, Jovanovic T, Mahan A, Kerley K, Norrholm SD, Kilaru V, Smith AK, Myers AJ, Ramirez M, Engel A, Hammack SE, Toufexis D, Braas KM, Binder EB, May V (2011) Post-traumatic stress disorder is associated with PACAP and the PAC1 receptor. Nature 470:492-497.

Riccio A, Li Y, Moon J, Kim KS, Smith KS, Rudolph U, Gapon S, Yao GL, Tsvetkov E, Rodig SJ, Van't Veer A, Meloni EG, Carlezon WA Jr, Bolshakov VY, Clapham DE (2009) Essential role for TRPC5 in amygdala function and fear-related behavior. Cell 137:761-772.

Robberecht P, Gourlet P, De Neef P, Woussen-Colle MC, Vandermeers-Piret MC, Vandermeers A, Christophe J (1992) Structural requirements for the occupancy of pituitary adenylate-cyclase-activating-peptide (PACAP) receptors and adenylate cyclase activation in human neuroblastoma NB-OK-1 cell membranes. Discovery of PACAP(6-38) as a potent antagonist. Eur J Biochem 207:239-246.

Roberto M, Brunelli M (2000) PACAP-38 enhances excitatory synaptic transmission in the rat hippocampal CA1 region. Learn Mem 7:303-311.

Roberto M, Scuri R, Brunelli M (2001) Differential effects of PACAP-38 on synaptic responses in rat hippocampal CA1 region. Learn Mem 8:265-271.

Roberts GW, Woodhams PL, Polak JM, Crow TJ (1982) Distribution of neuropeptides in the limbic system of the rat: the amygdaloid complex. Neuroscience 7:99-131.

Royer S, Martina M, Paré D (1999) An inhibitory interface gates impulse traffic between the input and output stations of the amygdala. J Neurosci 19:10575-10583.

Schaeren-Wiemers N, Gerfin-Moser A (1993) A single protocol to detect transcripts of various types and expression levels in neural tissue and cultured cells: in situ hybridization using digoxigenin-labelled cRNA probes. Histochemistry 100:431-440.

Shi S, Hayashi Y, Esteban JA, Malinow R (2001) Subunit-specific rules governing AMPA receptor trafficking to synapses in hippocampal pyramidal neurons. Cell 105:331-343.

Shin RM, Tsvetkov E, Bolshakov VY (2006) Spatiotemporal asymmetry of associative synaptic plasticity in fear conditioning pathways. Neuron 52:883-896.

Shioda S, Shuto Y, Somogyvari-Vigh A, Legradi G, Onda H, Coy DH, Nakajo S, Arimura A (1997) Localization and gene expression of the receptor for pituitary adenylate cyclase-activating polypeptide in the rat brain. Neurosci Res 28:345-354.

Shumyatsky GP, Malleret G, Shin RM, Takizawa S, Tully K, Tsvetkov E, Zakharenko SS, Joseph J, Vronskaya S, Yin D, Schubart UK, Kandel ER, 
Bolshakov VY (2005) Stathmin, a gene enriched in the amygdala, controls both learned and innate fear. Cell 123:697-709.

Sreedharan SP, Patel DR, Xia M, Ichikawa S, Goetzl EJ (1994) Human vasoactive intestinal peptidel receptors expressed by stable transfectants couple to two distinct signaling pathways. Biochem Biophys Res Commun 203:141-148.

Stella N, Magistretti PJ (1996) Vasoactive intestinal polypeptide (VIP) and pituitary adenylate cyclase activating polypeptide (PACAP) potentiate the glutamate-evoked release of arachidonic acid from mouse cortical neurons. J Biol Chem 271:23705-23710.

Sun N, Roberts L, Cassell MD (1991) Rat central amygdaloid nucleus projections to the bed nucleus of the stria terminalis. Brain Res Bull 27:651-662.

Tsvetkov E, Carlezon WA, Benes FM, Kandel ER, Bolshakov VY (2002) Fear conditioning occludes LTP-induced presynaptic enhancement of synaptic transmission in the cortical pathway to the lateral amygdala. Neuron 34:289-300.

Tye KM, Prakash R, Kim SY, Fenno LE, Grosenick L, Zarabi H, Thompson KR, Gradinaru V, Ramakrishnan C, Deisseroth K (2011) Amygdala circuitry mediating reversible and bidirectional control of anxiety. Nature 471:358-362.
Van Haastert PJ, Van Driel R, Jastorff B, Baraniak J, Stec WJ, De Wit RJ (1984) Competitive cAMP antagonists for cAMP-receptor proteins. J Biol Chem 259:10020-10024.

Vaudry D, Falluel-Morel A, Bourgault S, Basille M, Burel D, Wurtz O, Fournier A, Chow BK, Hashimoto H, Galas L, Vaudry H (2009) Pituitary adenylate cyclase-activating polypeptide and its receptors: 20 years after the discovery. Pharmacol Rev 61:283-357.

Villalba M, Bockaert J, Journot L (1997) Pituitary adenylate cyclaseactivating polypeptide (PACAP-38) protects cerebellar granule neurons from apoptosis by activating the mitogen-activated protein kinase (MAP kinase) pathway. J Neurosci 17:83-90.

Yang K, Lei G, Jackson MF, Macdonald JF (2010) The involvement of PACAP/VIP system in the synaptic transmission in the hippocampus. J Mol Neurosci 42:319-326.

Yang Y, Wang XB, Frerking M, Zhou Q (2008) Delivery of AMPA receptors to perisynaptic sites precedes the full expression of long-term potentiation. Proc Natl Acad Sci U S A 105:11388-11393.

Zucker RS, Regehr WG (2002) Short-term synaptic plasticity. Annu Rev Physiol 64:355-405. 